\title{
Synthesis and characterization of novel nanocomposites with nanofillers particles and their applications as dental materials
}

\author{
${ }^{1}$ Mohammed Ali Mutar, ${ }^{2}$ Mahdi Saleh Mahdi \\ Department of Chemical Engineering College of Engineering, University of AL-Qadisiyah, Iraq \\ mohammed.ali.@qu.edu.iq \\ Mohammeddw73@gmail.com
}

\begin{tabular}{l} 
Article Info \\
\hline Received, 2019 \\
\hline
\end{tabular}

\section{Keyword:}

Characterizan

Nanocomposite

Nanocomposites

Nano-particles

\begin{abstract}
Using copolymers materials in the preparation of dental fillings is now more common as a result for needs for more esthetic materials of filling and the international ban on the use of products that contain mercury, amongst others dental amalgams. On the other hand, a disadvantage with the Dental Nanocomposites is that they have a polymerization shrinkage. Particles of the filler are combined in the amongst other components for shrinkage minimization. Filler particle sizes have decreased lately and the majority of Dental Nanocomposites include Nano-particles . New Nanocomposites materials based on 2,2 propyl bisphenyl glycidyldimethacrylate (Bis-GMA) and unsaturated monomers ( Methacrylic

acid,Acrylicacid,2,2propylbisphenylglycidyldimethacrylate, Triethyleneglycoldimethacrylate ) with Nano inorganic fillers such as $\left(\mathrm{SiO}_{2}, \mathrm{ZrO}_{2}\right.$ and Hydroxyapatite) were characterized and synthesized for the sake of evaluating the potential applications they have in the field of dentistry, as restoration materials. The initial method was generating and characterizing new dental Nano-composites in presence of Triethylene glycol dimethacrylate (TEGDMA) as crosslinking agent. Composites which contain Bis-GMA and Triethylen glycoldimethacrylate) at the ratio (wt/wt) of 40/20, filled with various Nanofiller amounts (about 4.6\%wt) were produced. Photo-polymerization has been induced with camphoroquinone / N,N-dimethylaminoethyl methacrylate(CQ/DMAEMA) present, as a system of photo-initiation. Physicochemical properties, such as volumetric shrinkage (VS), water sorption (WS) and water solubility (WSL) were studied. Characterization is performed with the use of SEM and FTIR spectrum. SEM is utilized for showing the distributions of particle sizes and particle agglomeration of the treated Nanofillers in Nanocomposite. FTIR spectroscopy is initially utilized for identifying qualitative construction of the Nanocomposites. The Thermal stability of all dental Nanocomposites were also studied using the TGA and DSC techniques. The strength and the aesthetic characteristics of resin based Nanocomposite open the possibility of using it for each of the posterior and anterior restorations. Flexural strength, compressive strength, wear resistance and hardness were evaluated. The presented research has the aim of addressing current key utilizations of the practical Nanotechnology in the field of dentistry, most importantly, tooth structure restoration with Resin-based composites (RBCs) which benefit from the Nanoparticles.
\end{abstract}

\section{Corresponding Author:}

First Author,

Department of Chemical Engineering, College of Engineering, University of AL-Qadisiyah,Iraq

Email: mohammed.ali.@qu.edu.iq

Email: sarabmohammad100@yahoo.com 


\section{Introduction}

\section{Abstract}

Using copolymers materials in the preparation of dental fillings is now more common as a result for needs for more esthetic materials of filling and the international ban on the use of products that contain mercury, amongst others dental amalgams. On the other hand, a disadvantage with the Dental Nanocomposites is that they have a polymerization shrinkage. Particles of the filler are combined in the amongst other components for shrinkage minimization. Filler particle sizes have decreased lately and the majority of Dental Nanocomposites include Nano-particles . New Nanocomposites materials based on 2,2 propyl bisphenyl glycidyldimethacrylate (Bis-GMA) and unsaturated monomers

Methacrylic acid,Acrylicacid,2,2propylbisphenylglycidyldimethacrylate,Triethyleneglycoldimethacrylate ) with Nano inorganic fillers such as $\left(\mathrm{SiO}_{2}, \mathrm{ZrO}_{2}\right.$ and Hydroxyapatite) were characterized and synthesized for the sake of evaluating the potential applications they have in the field of dentistry, as restoration materials. The initial method was generating and characterizing new dental Nano-composites in presence of Triethylene glycol dimethacrylate (TEGDMA) as crosslinking agent. Composites which contain Bis-GMA and Triethylen glycoldimethacrylate) at the ratio (wt/wt) of 40/20, filled with various Nanofiller amounts (about 4.6\%wt) were produced. Photo-polymerization has been induced with camphoroquinone / N,N-dimethylaminoethyl methacrylate(CQ/DMAEMA) present, as a system of photo-initiation. Physicochemical properties, such as volumetric shrinkage (VS), water sorption (WS) and water solubility (WSL) were studied. Characterization is performed with the use of SEM and FTIR spectrum. SEM is utilized for showing the distributions of particle sizes and particle agglomeration of the treated Nanofillers in Nanocomposite. FTIR spectroscopy is initially utilized for identifying qualitative construction of the Nanocomposites. The Thermal stability of all dental Nanocomposites were also studied using the TGA and DSC techniques. The strength and the aesthetic characteristics of resin based Nanocomposite open the possibility of using it for each of the posterior and anterior restorations. Flexural strength, compressive strength, wear resistance and hardness were evaluated. The presented research has the aim of addressing current key utilizations of the practical Nanotechnology in the field of dentistry, most importantly, tooth structure restoration with Resin-based composites (RBCs) which benefit from the Nano-particles.

\section{Introduction}

Light-activated composites revolutionized modern restorative dentistry in the middle of the 60's and were improved in their performance properties, like esthetics, handling, and wear rate since then1.In recent years, with the development of nanotechnology, a new breed of composite resins, termed "Nanofillers composites", has been introduced into the dental market. Nanofillers composites were first mentioned in the early 1990s [1]. .Nanosized inorganic fillers have enabled the composite paste filler contents to be maximized at the same time as maintaining exceptional characteristics of clinical handling and at the same time minimizing the percentage of organic resin matrix.

To begin with, a UV source of light at 365 nanometer has been utilized for providing the needed energy of light, however, as a result of its shallow polymerization and iatrogenic side-effect it has been substituted with the visible light (which ranges between $427 \mathrm{~nm}$ and $491 \mathrm{~nm}$ ). Which is used presently and is still experiencing continuous progress. The composite development area keeps to witness constant progressions since its advent, and that increases the necessity for the practitioners in keeping up-to-date continuously. The mechanical, aesthetic, and physical characteristics of the complexes in addition to their clinical behaviors are dependent on their construction. Dental 
complexes mainly include 3 chemically distinct materials: the organic phase or organic matrix; the inorganic matrix, and that is the filler or the disperse phase. Researches and Developments concerning resin based complexes throughout the past ten years have produced various restorative material sub-species, such as the complexes of hybrid resins, the complexes of fine hybrid resins, and the micro-fill complexes [2]. Which has resulted in complexes of dental filling with considerably enhanced mechanical characteristics [3]. Although the properties of modern resin composites have improved, polymerization shrinkage is still a clinically significant problem. Even though composites that are based on Bis-GMA have become vitally important for dental restorations because of their more sufficient aesthetic quality, improved mechanical strength, and simple administration, there are remain a few issues. One of the significant issues of monomer phase is the fact that it undergoes the shrinkage of polymerization. Polymerization shrinkage [4] and successive stresses of contraction [5] might result in minimal discolorations, post-operative sensitivity, carpal displacement, secondary caries, and even cracks in the structure of the healthy tooth [6,7]. Which is why, the elimination or reduction in the volumetric contraction amount throughout polymerizing is a very significant issue in dental composites development. Bis-GMA forms the present-day complexes' basis because of its limited shrinkage and fracture resistance. Bowen's resin had honey viscosity, and as a result, small the filler particle amount which might be combined. Successive tests have includes Triethylene glycol dimethacrylate (TEGDMA) as a diluent for viscosity reduction. This combination of the monomer became a very commonly utilized combination of matrix monomer for dental composites up until now. Both those monomers include reactive double bonds, and in case of polymerization, form covalent bonds between the chains of the polymer, which are referred to as the cross-links, which enhanced the physical and mechanical characteristics [8]. It has been first utilized in a complex in the end of the 1960's .

The considerably small size of Nano-particles gives a low visual opacity in the unpigmented dental composite, allowing the researchers in preparing many different opacities and shades of the dental composites and thereby give very appealing restorations. In addition to that, Nano-filler particles that are spherically shaped give better polishability 6 and have the tendency of distributing the mechanical stress more evenly compared to the particles of irregular shapes, and that results in the improvement of the mechanical characteristics [9], due to the fact that flowable complexes are consistent, compatible, and easily manipulated, they are widely used in clinical practice. Flowable composite resins of new generation, with their increased filler ratios, may as well be utilized as materials of permanent restoration as a result of their enhanced mechanical and physical characteristics. Meanwhile, producers specify that Nanoparticle complexes that have been newly developed may be used in thick layers, in a similar way with conventional complexes [10]. Consequently, flowable composite resins can be applied as permanent restorative material in clinical applications [11].The main aim of the present study is checking whether those 5 monomers are capable of improving the polymer mechanical characteristics and network structure, in case of copolymerization. For the sake of achieving this aim, different compositions, which are usually used in dentistry practice, consist of TEGDMA and Bis-GMA in addition to unsaturated monomers (Methacrylic acid,Acrylicacid,2,2propylbisphenylglycidyldimethacrylate, Triethyleneglycoldimethacrylate ), have been modified by copolymerizing, respectively Bis-GMA with the unsaturated monomers. SEM morphology, flexural strength, compressive, wear resistance, and hardness. Volumetric shrinkage (VS), solubility (SL), and water sorption (WS) were studied. Characterization is performed with the use of SEM and FTIR spectrum. SEM is used for showing distributions of particle sizes and particle 
agglomeration of treated Nanofillers in Nanocomposite. Spectroscopy of FTIR is first utilized for identifying qualitative composition of Nanocomposites. The Thermal stability of all dental Nanocomposites were also studied using the TGA and DSC techniques.

\section{Experimental}

\subsection{1 Materials}

Methacrylic acid (MA) (MERCK), Acrylic acid (AA)( HIMEDIA), 2,2 propyl bisphenyl glycidyldimethacrylate (BIS GMA)(USA), Triethylene glycol dimethacrylate (TEG-DMA)( Aldrich), Zinc Oxide (ZnO)( GCC), Zirconium Oxide Nanoparticles $\left(\mathrm{ZrO}_{2}\right)$ ( Skyspring Nanomaterial), Silicon Oxid Nanoparticles $\left(\mathrm{SiO}_{2}\right)$ ( Skyspring Nanomaterial), Nano Hydroxy Apatite (HA)( Skyspring Nanomaterial), 2-(Diethyl amino)ethyl acrylate(ALDRICH), Camphorquinone(ALDRICH).

\subsection{2 Apparatuses}

Digital Sensitive Balance, Sarorius, B1210s, Germany, Mixter, Scanning Electron Microscopy (SEM)(JEOL,Japan), FTIR TENSOR 27, Fourier transform infrared spectroscope, BRUKER, Germany., (Thermogravimetry analysis (TGA) were performed on a polymer laboratories co England, Model pL-TG at Iran polymer \& petrochemical institute, using a heating rate of $10^{\circ} \mathrm{C} / \mathrm{min}$ in Argon atmosphere within the temperature range of $\left(25-800^{\circ} \mathrm{C}\right)$ (differential thermal analysis (DSC) measurement using apparatus (DSC) type (DSC 131 Evo, SETARAM) is the origin (France) in the college of education for pure science Ibn AL Haitham central service laboratory/University of Baghdad. properties were measured using a tensile testing machine from ( LARYEE Co)/ China. With a load cell of $20 \mathrm{kN}$ and a cross-head speed of 200 $\mathrm{mm} / \mathrm{min}$ at room temperature. The sample dimensions were accordance to ASTM D-412.

\subsection{3 Fabrication of Experimental Dental Nano-composites (A1-A3)}

The experimental dental Nano-composites have 2 series, which have been subjected to a process of fabrication through mixing fillers as well as the monomer matrix. Monomer matrix (Bis-GMA, MA, AA, and TEGDMA) has been subjected to mixing process in the mass ratio (40/20/20 and 20) for one hour. After that, a process of adding the zinc oxide $(0.5 \mathrm{gm})$ as antimicrobial agent has been implemented, also a process of adding Nanofillers $(0.7 \mathrm{gm})$ as colorant has been also implemented for improving the mechanical characteristics. After that, a process of adding DMAEMA $(0.5 \mathrm{wt} \%)$ as accelerator and camphorquinone $(0.5 \mathrm{wt} \%)$ as initiator has implemented and continuous for twenty minutes. Then, the paste has been inserted to the test moulds and the light cured with the use of a light curing unit (EliparFreelight2LED, $3 \mathrm{M} \mathrm{ESPE)} \mathrm{at} 1500 \mathrm{~mW} / \mathrm{cm}^{2}$ intensity. Light has been illuminated on the two surfaces, bottom and top, via clear matrix strips for forty seconds. Since it is majorly applied via clinicians, curing time of forty seconds has been applied for curing the experimental Nano-composites. Tip distance that is related to light curing unit has been kept at 1-2 $\mathrm{mm}$ from the surface of the surface. The concentration of materials is explained in table 1 . 
Table 1: Monomers and photo initiators used in this study

\begin{tabular}{|c|c|c|c|c|c|c|c|}
\hline \multirow[t]{2}{*}{$\begin{array}{c}\text { Sample } \\
\text { No. }\end{array}$} & \multirow{2}{*}{$\begin{array}{c}\text { Bis- } \\
\text { GMA } \\
(\%)\end{array}$} & \multirow{2}{*}{$\begin{array}{l}\text { MAA } \\
(\%)\end{array}$} & \multirow{2}{*}{$\begin{array}{l}\text { AA } \\
(\%)\end{array}$} & \multirow{2}{*}{$\begin{array}{c}\text { TEGDMA } \\
(\%)\end{array}$} & \multirow[t]{2}{*}{$\begin{array}{l}\text { Nano fillers } \\
\text { (0.7 gm) }\end{array}$} & $\begin{array}{c}\text { Photo } \\
\text { Initiator }\end{array}$ & $\begin{array}{c}\text { Accelerato } \\
\mathbf{r}\end{array}$ \\
\hline & & & & & & $\begin{array}{c}\text { Camphor- } \\
\text { quinone }\end{array}$ & " DMAEMA \\
\hline A1 & 440 & 20 & 20 & 20 & $\mathrm{Sio}_{2}$ Nano & 0.5 wt.\% & 0.5 wt. $\%$ \\
\hline A2 & 40 & 20 & 20 & 20 & $\mathrm{Zro}_{2} \mathrm{Nano}$ & 0.5 wt. $\%$ & 0.5 wt. $\%$ \\
\hline A3 & 40 & 20 & 20 & 20 & $\begin{array}{c}\text { Hydroxy } \\
\text { aptiate } \\
\text { Nano }\end{array}$ & 0.5 wt. $\%$ & 0.5 wt.\% \\
\hline
\end{tabular}
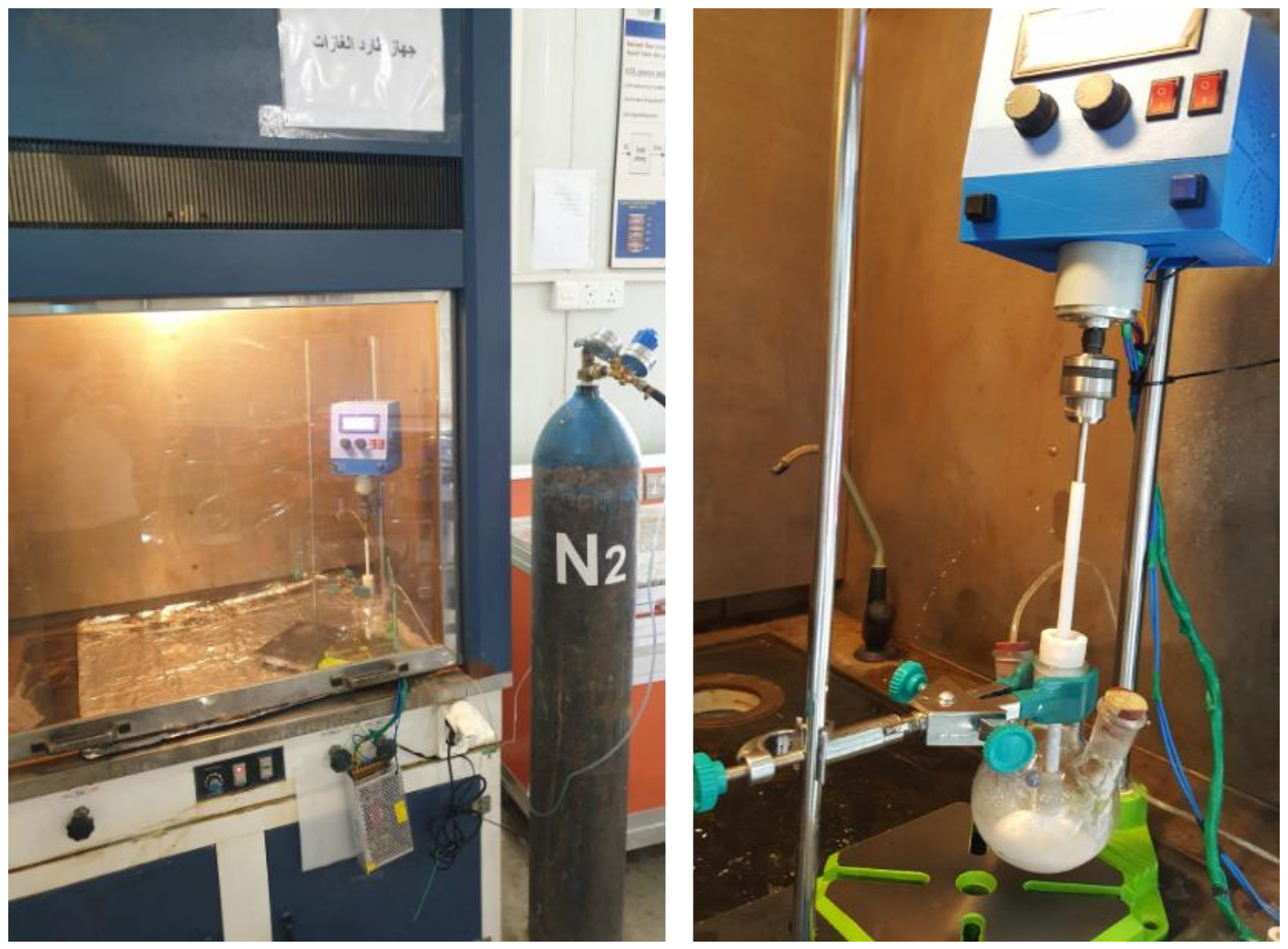

Fig 1: Experimental of composite dental.

\subsection{The Process of Curing}

The monomers have been mixed with: $0.4 \mathrm{wt} \%$ camphorquinone (CQ, Sigma-Aldrich) - the photosensitizer - and $1 \mathrm{wt} \% \mathrm{~N}$, N-di-methylaminoethylmethacrylate (DMAEMA, Sigma-Aldrich) — the reducing factor - and with vigorous stirring, poured to moulds-Petri dishes (with a diameter of $120 \mathrm{~mm}$ and thickness of $4 \mathrm{~mm}$ ). Those samples have been covered by PET film for the sake of reducing the impacts of the inhibition of oxygen and after that, irradiated, at a room temperature, for half an hour. Photo-polymerization has been started by a mercury vapor lamp of high pressure (FAMED1, model L6/58, Lodz, Poland, power 375W [12, 13]), which emits Ultra-Violet/VIS light, where camphorquinone is absorbed in a range between $420 \mathrm{~nm}$ and $500 \mathrm{~nm}$ [14]. 


\subsection{Measurement of Volumetric Shrinkage (VS)}

The VS related to dental resins has been examined via the variations in density pre and post the process of photo polymerization, also, the Archimedes principle has been used to determine the density. Measurement has been implemented with the use of commercial Density Determination Kits related to the analytical balance Mettler ToledoX on basis of ISO17304:2013 (E). A glass dish has been utilized for the purpose of measuring density related to un-polymerized sample. Initially, the glass dish's mass has been weighed in water as well as air, also the glass dish's density ( $\rho g d$ ) has been estimated on the basis of the Equation (1):

$$
\varrho_{p s}=\frac{m_{p s 1} \times \varrho_{0}}{m_{p s 1}-m_{p s 2}}
$$

In which $Q_{o}$ represent the water's density, mgd1 as well as mgd2 representing glass dish's density in air as well as in water. To measure the glass dish's density has been repeated 3 time for the purpose of obtaining mean value $\varrho$ (gd.m). After that, some amount of un-polymerized sample has been dispensed in glass dish, total mass related to the glass dish and the sample has been weighed in water as well as in air, also, density related to unpolymerized sample @up has been estimated on the basis of Equation (2)

$$
\varrho_{u p}=\frac{m_{u d 1}-m_{g d 1}}{m_{u d 1}-\left(\frac{m_{g d 1} \times \varrho_{0}}{\varrho_{g d . m}}\right)-m_{u d 2}} \times \varrho_{0}
$$

In which mgd1 can be defined as the glass dish's mass in air, mud1 can be defined as mass related to glass dish and un-polymerized sample estimated both in air, mud2 can be defined as mass related to glass dish and un-polymerized sample estimated both in water, @gd.m can be defined as the glass dish's mean density, @o represent the water's density. Following measurement process, glass dish has been cleaned thoroughly, also the measurement process has been repeated on 4 more samples for getting mean value related to density regarding the un-polymerized sample $\varrho_{u p, m}$.

Resins have been poured in steel mold that have the size ( 2 millimeters _ 2 millimeters _ 25 millimeters), after that they were light-cured through the use of same dental source of light as can be seen in the DC measurements (60s for 1 portion up to the point where the entire sample has been irradiated). The mass that is related to polymerized sample (size) has been weighed in water as well as in air, density related to polymerized sample $\rho p$ s has been estimated on the basis of Equation (3)

$$
\varrho_{p s}=\frac{m_{p s 1} \times \varrho_{0}}{m_{p s 1}-m_{p s 2}}
$$

Where, $Q_{0}$ can be defined as the water's density, mps1 represent the mass related to polymerized sample in the air, mps 2 represent mass related to polymerized sample in the water. Measure process on the polymerized sample has been repeated 5 times for the purpose of obtaining mean value regarding density of polymerized sample @ ps.m. Lastly, sample's volumetric shrinkage has been estimated on the basis of Equation (4)

$$
\mathrm{VS}=\frac{\varrho_{p s, m}-\varrho_{u p, m}}{\varrho_{p s, m}} \times 100 \%
$$

\subsection{Measurement of Water Sorption (WS) and Solubility (SL)}


Resins have been poured in cylindrical steel mold (1.00 millimeter in height and 15-millimeter internal diameter) between 2 transparent Mylar sheets, in addition to glass slide of (1 millimeter) thickness has been utilized for covering upper surface. Then, samples have been irradiated (60s) for 1 portion up until whole sample has been irradiated) through the use of same dental light source as can be seen in DC measurements. There are 5 specimens have been prepared for each one of the dental resin systems. Initial weight (M1) related to each one of the specimens has been estimated through the use of electronic balance (MettlerA30, Mettler Instrument Co., High stone, NJ, USA) with $(0.1 \mathrm{mg})$ accuracy. Then, the specimens have been put in (30 milliliter) distilled water, then stored at a temperature of 37 Celsius. Then, at fixed intervals of time, they have been removed, and then blotted dry for the purpose of removing any excess water, after that they have been reweighed and returned into water. At thirty days of immersion, no considerable variance in mass has been seen, also M2 has been acquired as an equilibrium mass. Specimens have been dried at a temperature of sixty Celsius up to the point where their mass remains constant, result has been recorded as M-3. WS and SL have been estimated through the use of Equations (5) and (6):

$$
\begin{aligned}
& \mathrm{WS}=\frac{M_{2}-M_{3}}{V} \times 100 \% \\
& \mathrm{WSL}=\frac{M_{1}-M_{3}}{V} \times 100 \%
\end{aligned}
$$

\subsection{Scanning Electron Microscopy (SEM)}

Researches on the Morphology have been carried out on the cured materials' fractured surfaces with Hitachi TM3000 SEM, Tokyo, Japan. Sample surfaces, prior to observations, have been sputter coated in gold.

\subsection{Physico-mechanical properties of the test samples}

\subsubsection{Flexural characteristics}

The flexural strength $(\sigma)$ and the flexural modulus (E) have been specified according to the ISO178 in the tests of 3-point bending, with the use of a universal machine of testing ("INSTRON, model TT-CM, Norwood, MA, US") [16]. Rectangular UDMA polymer samples (length*width*thickness: $80 \mathrm{~mm} * 10 \mathrm{~mm} * 4 \mathrm{~mm}$ ) have been cut from the moulds, prepared in way that has been explained earlier. E and $\sigma$ have been computed by respectively following the formulas below:

$$
\begin{aligned}
& \mathrm{E}(\mathrm{Mpa})=\frac{P 1 l^{3}}{4 b d^{3} \sigma} \\
& \sigma(\mathrm{Mpa})=\frac{3 P 1}{2 b d^{2}}
\end{aligned}
$$

P represents the maximal load; 1 represents the distance between supports; P1 represents load at the chosen elastic region point of stress-strain plot; $d$ denotes the specimen's thickness; and b denotes its width.

\subsubsection{Hardness}

Ball indentation hardness (HB) has been specified based on the ISO2039-1, on test samples that are shaped like discs $(120 \mathrm{~mm}$ diameter $\times 4 \mathrm{~mm}$ thickness), with the use of the apparatus of VEB Werkstoffprüfmaschinen ("Leipzig, Germany”) [17]. HB has been computed based on: 


$$
\mathrm{HB}(\mathrm{Mpa})=\frac{F m\left(\frac{0.21}{h-h^{1}-0.21}\right)}{\pi \mathrm{dhr}}
$$

Fr represents the decreased test load; $d$ represents ball indenter diameter $(\mathrm{d}=5 \mathrm{~mm})$; $\mathrm{hr}$ represents decreased impression depth $(\mathrm{hr}=0.25 \mathrm{~mm})$; $\mathrm{h}$ represents the impression depth; Fm represents test load on indenter $(\mathrm{Fm}=490 \mathrm{~N})$.

\subsubsection{Compression set:}

Compression set was measured according to ISO 1653 at ambient temperature.

\subsubsection{Wear resistance-:}

Wear resistance was measured at $370 \mathrm{C}$ and for forty-eight hours. Test has been run for 100000 cycles at $1.2 \mathrm{~Hz}$. The stainless-steel balls (Small Parts Inc., radius=2.4 millimeter) have been applied as antagonists.

\section{Results and Discussions}

\subsection{Prepared Polymers Synthesis and Characterization}

\subsubsection{Synthesis and FTIR spectrum of (A)}

The preparation of polymer (A) has been done via co-polymerization process that is related to the MA, AA, Bis-GMA, with cross-linker (TEGDMA),in the presence of camphoroquinone as photoinitiator and N,N-dimethylaminoethyl methacrylate as accelerator the reaction was continued through a process of mixing for 40 minutes and at room temperature under N2 gas for the purpose of removing dissolved oxygen, just as can be seen in reaction scheme (1):

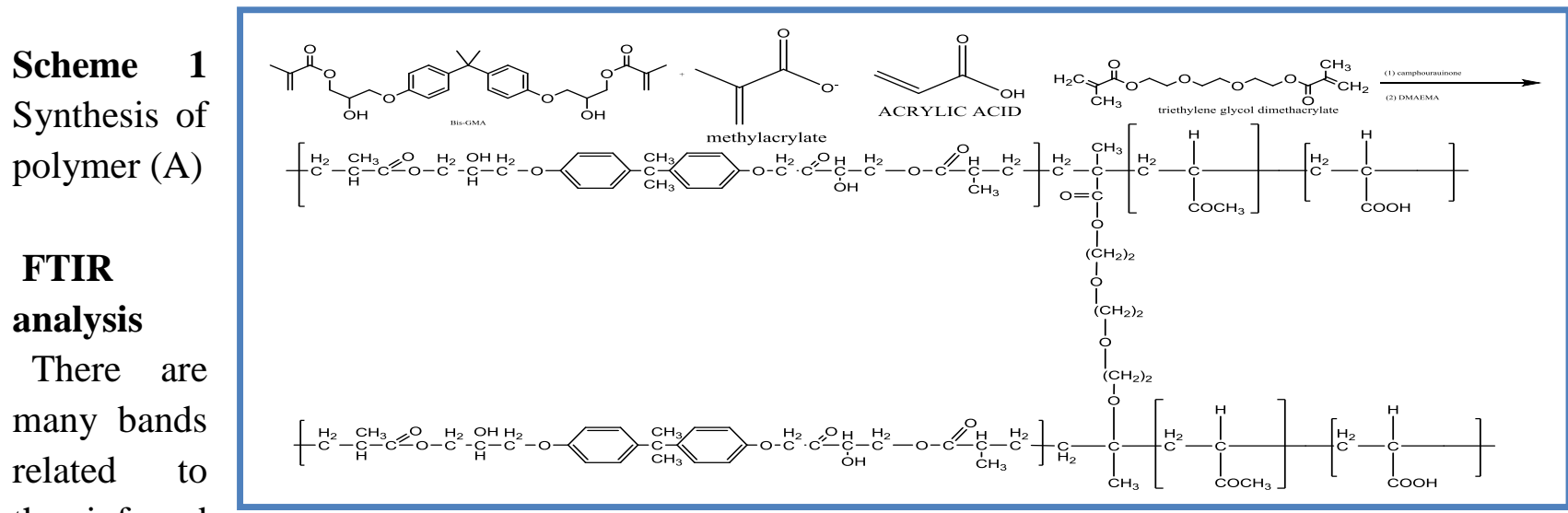

the infrared

spectrum, majorly the wide range in range of $(3300-3450) \mathrm{cm}^{-1}$, that indicate overlaps the current absorption $(\mathrm{OH})$. Appearance of the beams in range of $\left(2850-2990 \mathrm{~cm}^{-1}\right)$ to vibratory vibration that is related to aliphatic $\mathrm{CH}$ bonds in polymer's structure. Characteristic beams at $1750 \mathrm{~cm}^{-1}$ indicate $(\mathrm{C}=\mathrm{O})$ of acid's group, moreover, characteristics beam at $1725 \mathrm{~cm}^{-1}$ indicate the $(\mathrm{C}=\mathrm{O})$ vibration of ester group, aromatic $(\mathrm{C}=\mathrm{C})$ are indicated at range of $\left(1475-1600 \mathrm{~cm}-{ }^{1}\right)$. Characteristic bands in range of $\left(1390-1400 \mathrm{~cm}^{-1}\right)$ are the result of $(\mathrm{C}-\mathrm{H})$ bonds for the $(\mathrm{CH} 3)$ group of polymers. The absorption bands in range of $\left(1000-1100 \mathrm{~cm}^{-1}\right),(\mathrm{C}-\mathrm{O})[18,19]$, as can be seen in Fig 3: 


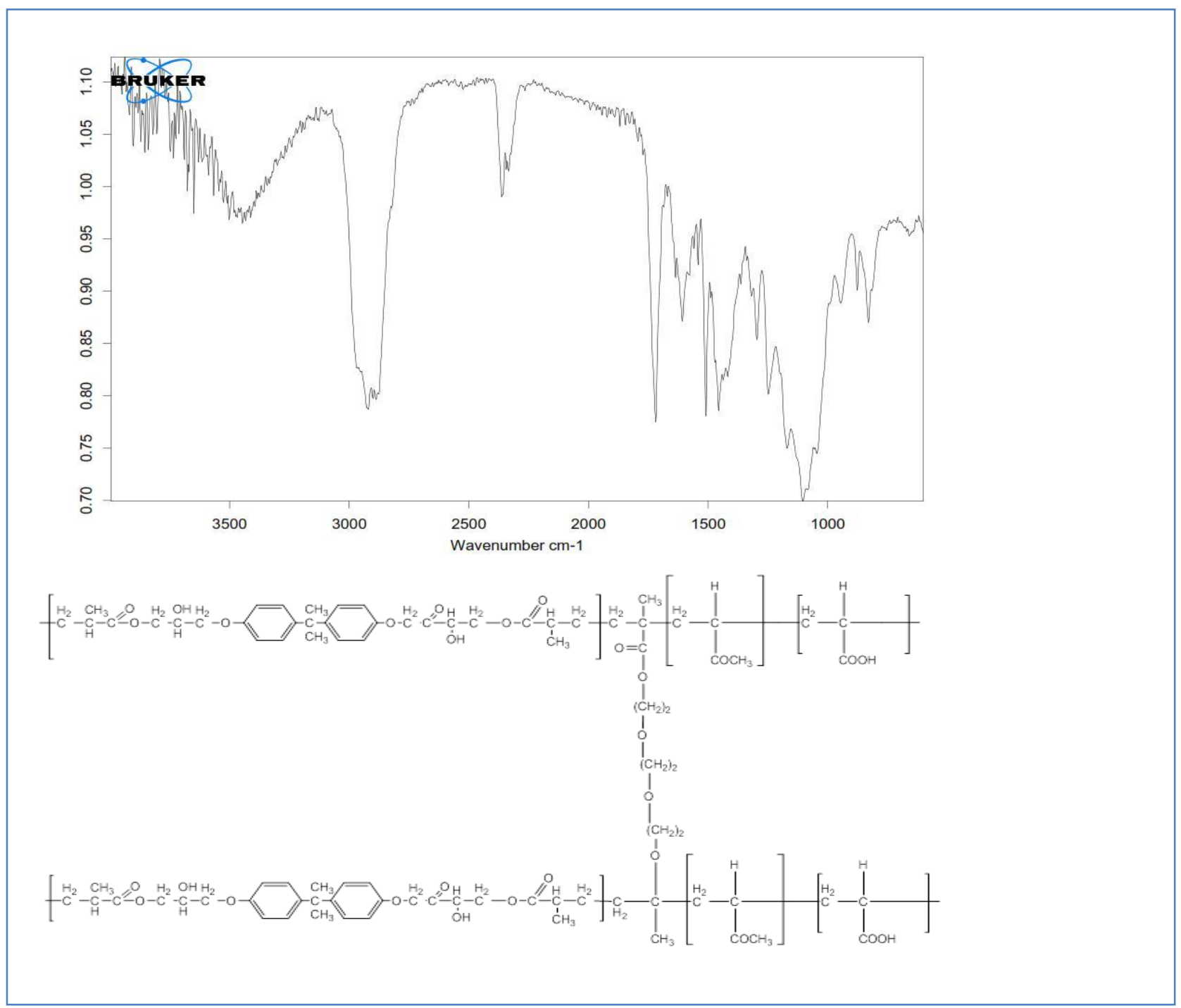

Fig 3. FTIR spectra for (A)

\subsubsection{Water Sorption and Solubility (WS)}

Water sorption (WS) and solubility (SL) have been acquired on the basis of ISO4049 [20]. Steel split mold has been utilized for making the specimens with diameter of (15 millimeter) and (1 millimeter) thick $(n=5)$. WS has been decreased reduced through using extra hydrophobic monomer, preventing the hygroscopic expansion. Water sorption might be accounted for the adverse effects such as discoloration and subsequent swelling of restorative materials .

With regard to the presented study, there has been an increase in the water sorption with the reduction in conversions of the tested formulation. Because of their molecule's hydrophobic character, as well as the elevated conversion, Bis-GMA presented with the lowest water sorption [21]. With regard to the TEGDMA, elevated conversions do not translate to elevated cross-linking density, as mentioned earlier, thus second to last lowest water sorption has been fairly unpredicted [22], also it should be associated with its low hydrophilicity in comparison to Bis-GMA. Very comparable water sorption values have been shown by hydrophobic monomers and Bis-GMA, despite differences in the conversion, possibly due to the fact that these are considered to be the major hydrophilic molecules assessed in the presented study. 
In addition to being dependent on hydrophilic character and amount of leachable in products, the results of solubility are on the basis of amount of water absorbed in network. Furthermore, the pendant double bonds which are contributing to greater free volume to network [23] and favor WS, could not be contributing to the leachable species (oligomers and monomers), due to the fact that they're tied to network. This might explain the reason behind solubility values being related to BisGMA have not been greatest among homopolymers, regardless of its considerably more elevated WS.TEGDMA, at the same time, because of tendency to cyclization, indicated the highest results of SL, despite low water sorption and high conversion, probably due to the fact that the oligomers of low-molecular-weight have been existent and ready for leaching. The low SL results from the BisGMA have been clarified through the hydrophobic character as well as the high conversion (with regard to this condition, possibly also with greater cross-linking) of molecule. Also, it must be indicated that the results of SL could be undervalued for more hydrophilic monomer, due to the fact that the water yield stronger hydrogen bond interaction with the hydroxyl and (in Bis-GMA), as well as weak bond with the ethylene glycol unit (which are presented in great concentrations in TEGDMA), the could be hindering the water elimination throughout the 2 nd period of storage in desiccators [22]. It appears that the distinct characteristics which are related to tested dimethacrylate homopolymers are the cause of their unique behavior with regard to the flexural properties, polymerization kinetics, WS and SL. These properties explain using the co-polymers for the purpose of obtaining high DC and mechanical characteristics, in addition to optimum resistance to water degradation.

It can be indicated that, the before water immersions Bis-GMA-based resin had similar after water immersions, which can be an indication of its more effective water resistance. WSL reveal the amount of the un-reacted monomers which are leached out of the polymeric networks. The major cause of tissue inflammation as well as cytotoxicity is the monomers' release [24]. It has been indicated that Degree of conversion (DC) and WSL are related, and low WSL could be the result of high DC [25]. This must be based on un-reacted monomers' leachability in polymeric networks. Intermolecular hydrogen bond that is created via - $\mathrm{NH}$ - is weaker than the hydrogen bond created via $-\mathrm{OH}$, due to the $-\mathrm{OH}$ group's high cohesive energy density [25]. Thus, unreacted monomers can undergo a process of absorption to surrounding networks more firmly in Bis-GMA-based polymers in addition to being to leach out of polymers, which might lead to low WSL regarding the Bis-GMAbased polymers. Bis-GMA monomers result in more hydrophobic molecule; thus, the materials will have less susceptibility to liquid's sorption as can be seen in fig 4 .

Since the polydimethacrylates can be considered as cross-linked dental polymers, and because of the polymer chains have cross-links between them, this will typically lead to considerable reduction in polymer's solvent permeability since the reduce the capability related to polymer chain for swelling as well as reducing hole free volume [26]. Nevertheless, WS could be defined as needed impact as the composites' hygroscopic expansion was indicated to the close marginal leakage gap because of the shrinkage [27]. At the same time, a significant standard for the dental composites is the sufficient resistance to degradation via water and other solvents. It has been indicated that the dental composites are leaching only (0.02-0.05 percent) of their total mass to the aqueous solution through the first thirty days, this is the result of inorganic (Nanofillers). 


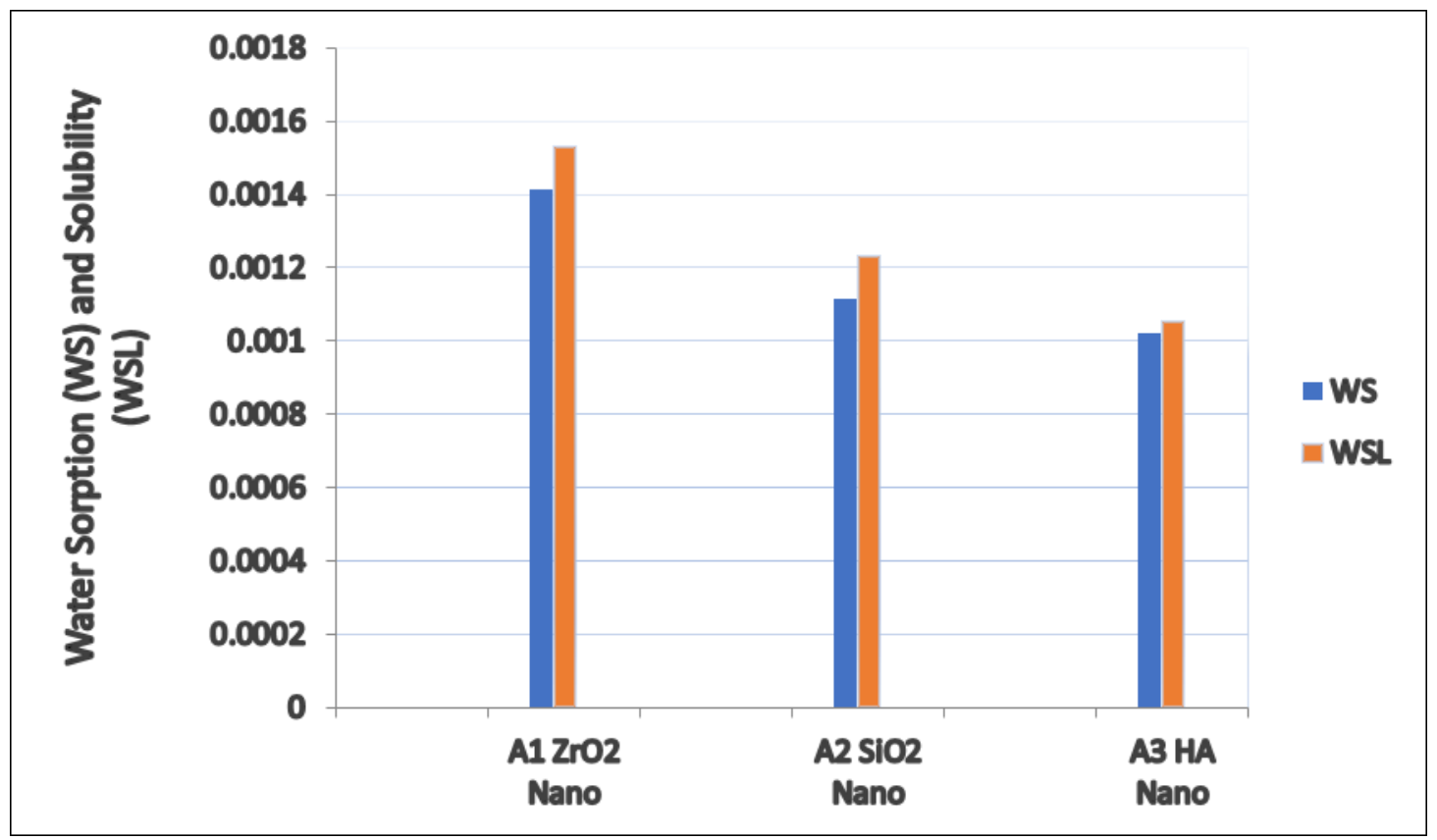

Fig 4: Water sorption (WS) and water solubility (SL)

\subsubsection{Volumetric Shrinkage}

The Volumetric Shrinkage (VS) values which are related to the specimens of the composites have been assessed on the basis of Archimedes principle. Uncured sample has been left to rest for one minute for the purpose of eliminating the impact of the slumping on measurements, then it has been exposed to 40s light curing, and the curing unit tip was placed at a distance of (1-2 millimeter) from specimen. The assessment has been implemented through the use of commercial Density Determination Kit of analytical balance Mettler Toledo X on the basis of ISO17304:2013 (E).

One of the main disadvantages, particularly in the dental composites is that their polymerization shrinkage could result in secondary caries and marginal gaps in restored teeth. Shrinkage is caused by the composites' matrix-phase polymerization, also it is a main disadvantage in the dental resinmonomer. The polymerization of resin is accompanied by the volumetric shrinkage. As the polymerization proceeds, van deer Waals distances have been modified to covalent bond distance which results in volumetric shrinkage. The shrinkage degree is represented through the number of the created covalent bonds that is defined as the polymerization reaction's extent. Another reason for the volumetric shrinkage is that the molecular distances between polymer chains become smaller than the molecular distance between monomers [28] .

Since the stresses generated from polymerization shrinkage cause defects of deboning at the toothrestorative interface $[29,30]$, one of the main issues in the dental composites is to eliminate or decrease the polymerization shrinkage. In the case when the monomer in the proximity react to create covalent bonds, there will be a reduction in the distance between atoms groups, also the free volume will be decreased, that will lead to VS magnitude experienced through composites has been decided through its filler volume fraction as well as the conversion's degree and composition of resin matrix. As shown in fig 5. the composite with the Bis-GMA presented much smaller volumetric shrinkage. The shrinkage values which has been indicated for Bis-GMA (forty percent ) and TEGDMA (twenty percent) have been considerably more elevated than the shrinkage values related to the standard composites, that are in the range of $2-3$ percent $[31,32]$. Such difference is the 
result of the fact that in the hybrid composite, about sixty percent of volume has been occupied through filler particle. Even though that the inorganic content related to micro filled composites is approximately forty percent, their shrinkage values are considered to be comparable to hybrids, because of the existence of pre-polymerized composite particle, occasionally indicated as "organic fillers", that will be rendering them in a way comparable to the hybrid composite with regard to actual volume fraction regarding the polymerizing resin. The shrinkage will also be affected via the diluents' concentrations in resin matrix .

A new study indicated that high ratios of TEGDMA/Bis-GMA in the experimental composite will lead to high contraction stress value because of the elevated VS, due to the improved conversions [33]. Due to the fact that they usually have low molecular weights in comparison to host monomers, the density of the polymerizable carbon double bonds will be increased via the "diluents" monomers that will result in more shrinkage. Also, the reaction environment's mobility will increase because of the Tg as well as low viscosity of diluent, which will allow more effective conversions [34]

Previous studies showed that increasing light intensity resulted in more polymerization shrinkage for some composites, but not all materials [35,36]. In our study, the effects of each curing mode on two composite resins were compared and no significant difference was observed. Each composite showed similar behavior in the face of modulation of the light intensity during photoactivation. Therefore, it must be put into perspective that this result is valid only for two resin composites in this study. Consequently, with regard to this study's limitations, it might be indicated that the increase in the shrinkage of composites is related to the total energy of curing lights. Further research in this area is necessary in order to reveal the polymerization shrinkage of other composite resins.

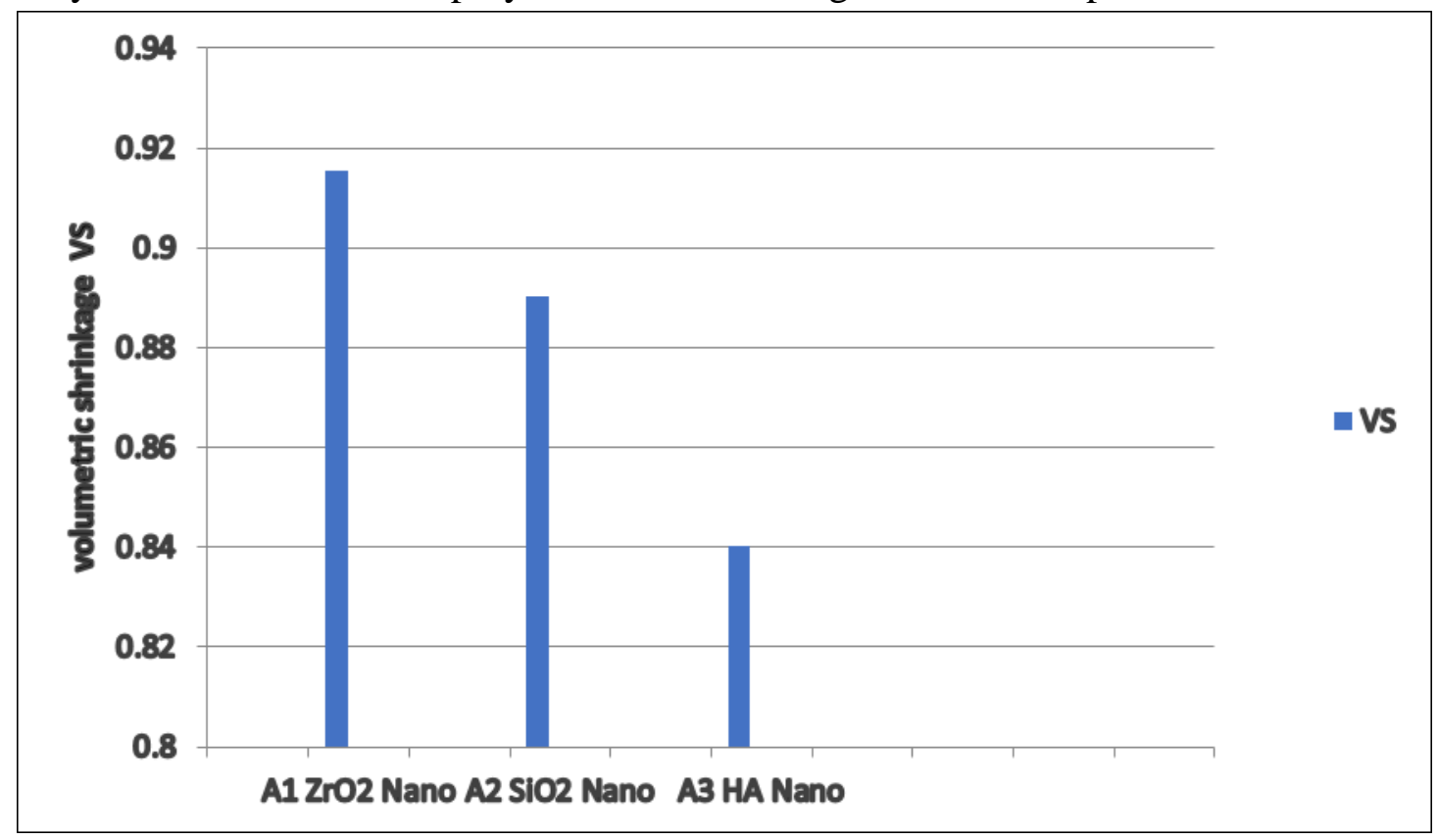

Fig 5: Volumetric Shrinkage

\subsubsection{Scanning Electron Microscopy}

Monodispersed and spherical Nanoparticles were successfully synthesized. SEM was used to evaluate both the morphology of Nanoparticles and fillers composite surface following the fracture toughness test (SEM, LEO (Zeiss) 1540XB). Samples were prepared for SEM by placing a small amount of the sample powder on SEM tubes followed by coating with osmium in order to prevent 
charging of the samples and to reduce the Nanotube damage from the electron beam during imaging. Surface treatment has been of high importance to develop and efficient dental composites. In the case when the filler's size is not more than thirty nm, agglomerations as well as aggregation of the Nanoparticles will occur. Thus, interfacial adhesions between the filler and the polymer matrix will be improved via the agglomeration filler dispersion. The improvements in the mechanical and surface characteristics might be the result of these enhancements. With regard to the presented study, zirconium oxide as well as Nano-silica have been applied as filler, that has been mixed with various concentrations chosen of the monomer resin in addition to the additives for the dental restorative applications. Using zirconium oxide fillers and Nano-silica have been anticipated to have benefits and enhance the characteristics related to composite fabricated. Klapdhor and Moszner 14 have indicated that the mono-dispersed Nano-filler in polymer matrix result in Nano-composite material of optimum mechanical characteristics, excellent process ability as well as high transparency .

Group A1. In this group was used (Bis-GMA, MA, AA) monomers at different concentration and

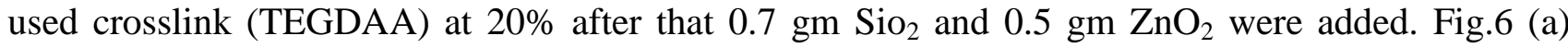
shows that spherical shapes with different size range of $12.7-71.2 \mathrm{~nm}$ of $\mathrm{SiO}_{2}$ in dental composites were obtained. The SEM micro-graph that is related to each one of the materials has been displayed in the Fig 6. $(a \& b)$ at 2 distinctive magnifications.

\section{Group A1}
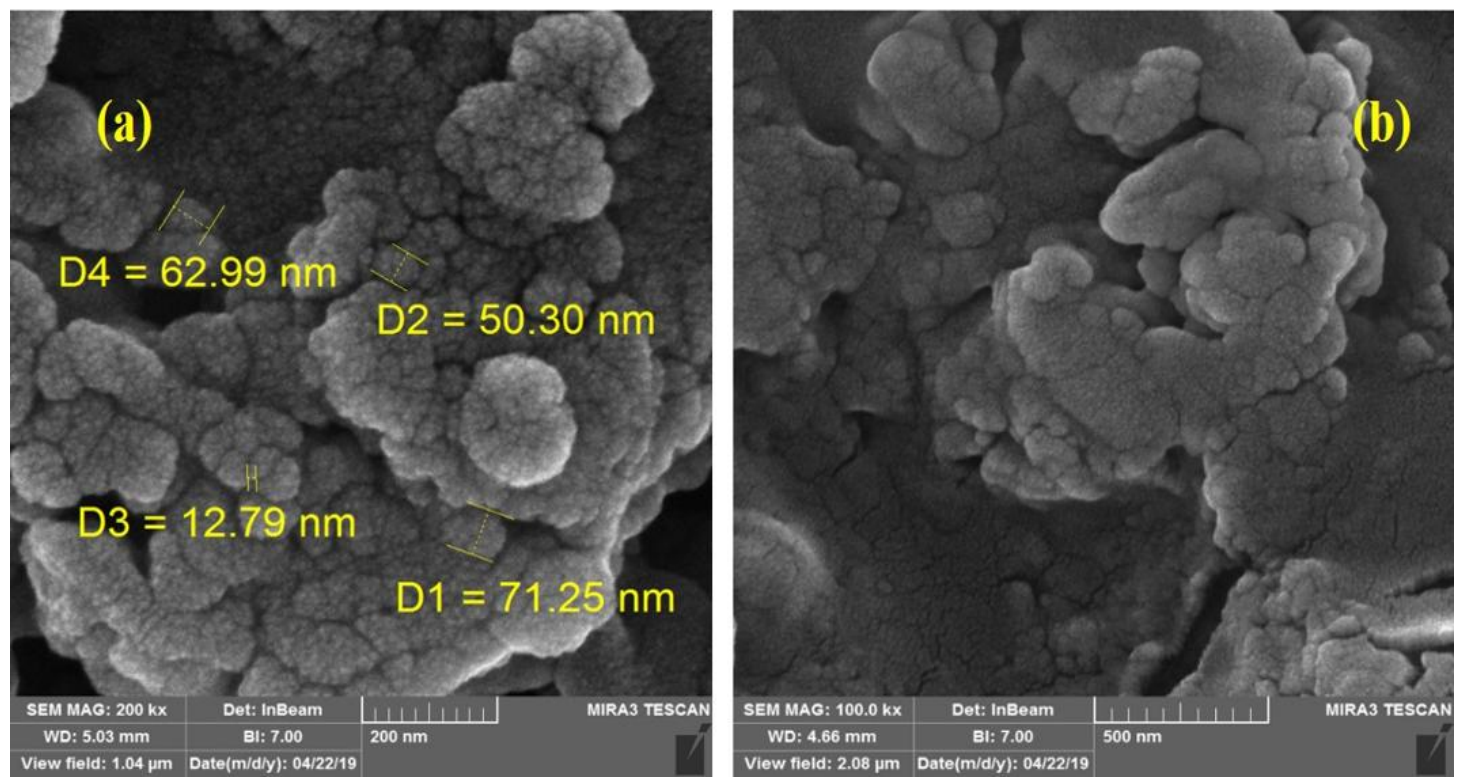

Fig 6 (a \& b): SEM image of Nanosilica composite

From Group A 2. In this group was used same monomers as in group A1 but the different from group A1 only in Nanofiller which was used $0.7 \mathrm{gm} \mathrm{ZrO}_{2}$ were added. Fig.7 (a) shows that spherical shapes with different size range of $20.8-77.4 \mathrm{~nm}$ of zirconium oxide Nanoparticles composite with monomer were obtained. SEM micrograph of each material is shown in Fig. 7 (a \& b) at two different magnifications. 


\section{Group A2}
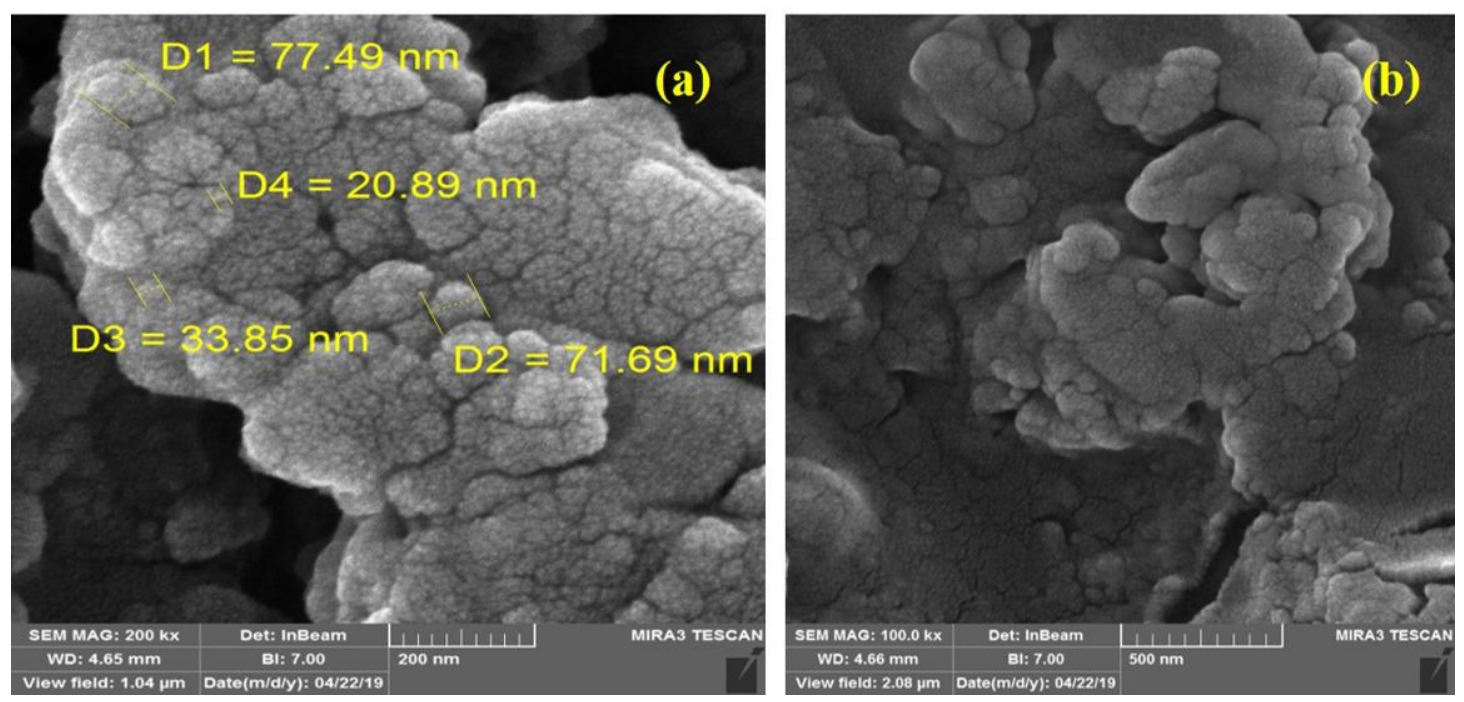

Fig 7 (a \& b): SEM image of zirconium oxide Nanoparticles composite

\subsubsection{Thermal gravimetric analysis (TGA) study}

Thermogravimetric Analysis determine the change in mass as temperature's functions. It can be mainly applied to specify degradation temperature, material's absorbed content, the level of inorganic as well as the organic parts in the materials as well as residues of analysis solvent. It does use sensitive electronic balance through which a sample will be suspended in furnace, which is controlled through temperature programmer. Thermal characteristics of 4 samples of such polymers have been examined by TGA in Argon atmosphere at heating rate $\left(10^{\circ} \mathrm{C}\right.$ per minute) [37-39]. With regard to this test, many values have been recognized including Ti, Top, Tf, T50\%, Residue at 600 Celsius, and char yields at 400 Celsius as can be seen in (Table 2) .

Temperatures of fifty percent weight loss of (DNC A1- DNC A3) of polymers have been between (330-409) ${ }^{\circ} \mathrm{C}$, The char results of (DNC A1)are 78\%,(DNC A2)are 74\%, (DNC A3)are 72\% at 500 ${ }^{\circ} \mathrm{C}$ in Argon atmosphere, indicating that they could satisfy the requirements of temperature resistance that may be utilized in a variety of applications. Weight residue of (DNC A1) are 80\%, (DNC A2) are $76 \%,(\mathrm{DNC} \mathrm{A} 3)$ are $74 \%$, at $600{ }^{\circ} \mathrm{C}$.

Table 2: Some Thermal Stability Characteristics Curves Thermal Gravimetric Analysis (TGA) of polymers represents the temperature of decomposition.

\begin{tabular}{|c|c|c|c|c|c|c|}
\hline DNC & $\mathbf{T}_{\mathbf{i}}$ & $\mathbf{T}_{\mathbf{o p 1}}$ & $\mathbf{T}_{\mathbf{f}}$ & $\mathbf{T}_{\mathbf{5 0} \%}$ & $\begin{array}{c}\text { Residue } \\
\mathbf{a t}^{\mathbf{0}} \mathbf{C 6 0 0}\end{array}$ & $\begin{array}{c}\text { Char \% } \\
\text { At } \\
\mathbf{5 0 0}^{\mathbf{}} \mathbf{C}\end{array}$ \\
\hline $\mathrm{A} 1$ & 318 & 360 & 441 & 402 & 80 & 78 \\
\hline A2 & 195 & 231 & 459 & 369 & 76 & 74 \\
\hline A3 & 306 & 348 & 463 & 385 & 74 & 72 \\
\hline
\end{tabular}


DNC Dental Nano Composite

Top represents optimal temperature of decomposition.

Ti represents the temperature of the initial decomposition.

T50\% represents the temperature of 50\% weight loss, which has been obtained from the TGA.

Tf represents the final temperature of decomposition. The final degree of dissociation temperature

Char \% at $400{ }^{\circ} \mathrm{C}$ represents the residual weight percentage at $500^{\circ} \mathrm{C}$ in Argon by TGA

\subsubsection{Differential Scanning Calorimeter Analysis (DSC) Study}

Differential Scanning Calorimetry, is a technique of thermal analysis that investigates how material's heat capacity $(\mathrm{Cp})$ is transformed by temperature. A known mass sample is heated or cooled and the variations in its heat capacity are observed as alterations in the heat flow. This allows to reveal transitions such as melts glass transitions (Tg), and the melting point $(\mathrm{Tm})$ the crystallization degree (Tc) (20). The results of (DNC A1) polymer showed in figure (8) the value of the glass transition $(\mathrm{Tg})$ of the mixture $\left(120^{\circ} \mathrm{C}\right)$, indicating an increase in the flow of temperature and then increase the rate of absorption of the sample to the temperature until the melting point $(\mathrm{Tm})$ at $\left(597^{\circ} \mathrm{C}\right)$ if completely melted and then the rate of absorption of the sample to heat and by the curve was set the crystallization rate $(\mathrm{Tc})$ of the mixture $\left(151.7^{\circ} \mathrm{C}\right)$. The results of (DNC A2) showed in figure (8) the value of the glass transition $(\mathrm{Tg})$ of the mixture $\left(111^{\circ} \mathrm{C}\right)$, indicating an increase in the flow of temperature and then increase the rate of absorption of the sample to the temperature until the melting point $(\mathrm{Tm})$ at $\left(568^{\circ} \mathrm{C}\right)$ if completely melted and then the rate of absorption of the sample to heat and by the curve was set the crystallization rate $(\mathrm{Tc})$ of the mixture $\left(135^{\circ} \mathrm{C}\right)$. The results of (DNC A3) polymer showed in figure (8) the value of the glass transition ( Tg) of the mixture $\left(118^{\circ}\right.$ C), indicating an increase in the flow of temperature and then increase the rate of absorption of the sample to the temperature until the melting point $(\mathrm{Tm})$ at $\left(585^{\circ} \mathrm{C}\right)$ if completely melted and then the rate of absorption of the sample to heat and by the curve was set the crystallization rate (Tc) of the mixture $\left(145.4^{\circ} \mathrm{C}\right)[40]$.

Table 3: Shows the Degree of Glass Transition, Melting Point and the Degree of Crystallization in the Differential Thermal Analysis

\begin{tabular}{|c||c||c||c|}
\hline DNC & Tg $\left(\mathbf{c}^{\mathbf{0}}\right)$ & TM $\left(\mathbf{c}^{\mathbf{0}}\right)$ & TC $\left(\mathbf{c}^{\mathbf{0}}\right)$ \\
\hline \hline A1 & 120 & 597 & 151.7 \\
\hline \hline A2 & 111 & 568 & 135 \\
\hline A3 & 118 & 585 & 145.4 \\
\hline
\end{tabular}

DNC Dental Nano Composite

\section{Tg: Degree glass transition}

Tm: Melting Point

Tc: Degree of crystallization 
A1

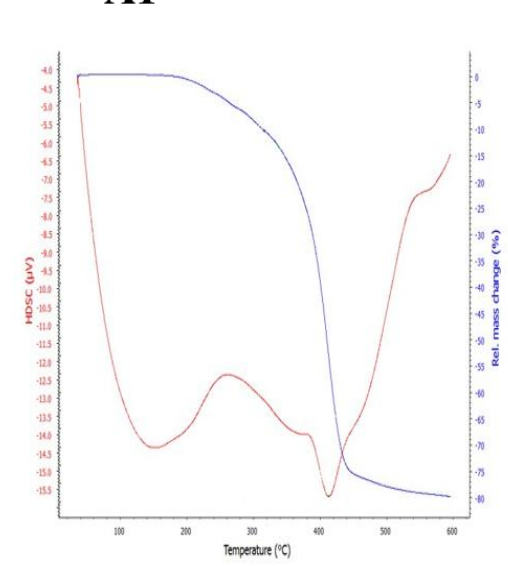

A2

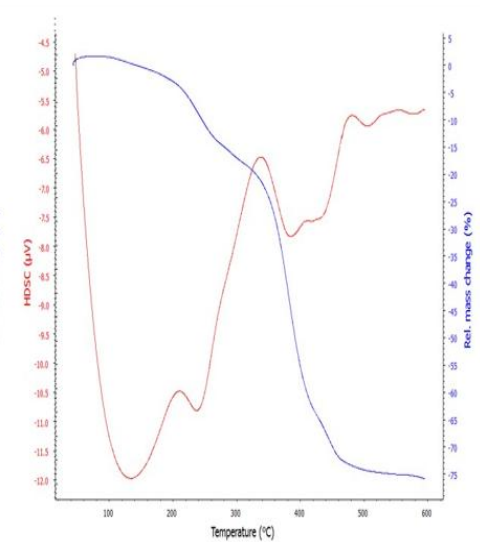

A3

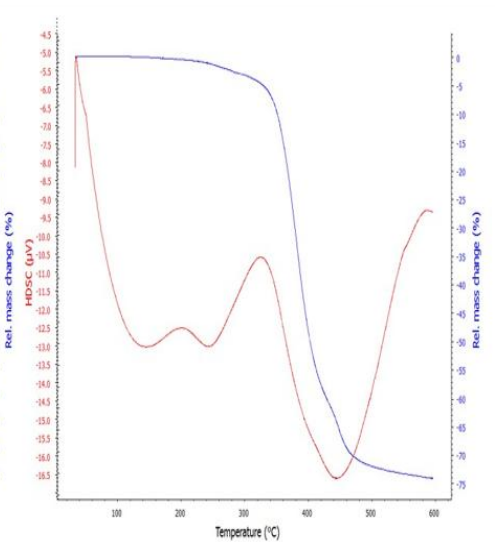

Fig 8: TGA and DSC for A1) composite dental with $\mathrm{Zro}_{2}, \mathrm{~A} 2$ ) composite dental with $\mathrm{SiO}_{2}$ and A3) composite dental with HA.

\subsection{Effect of type and content of Nano fillers}

A lot of Nano-fillers types, including $\left(\mathrm{HA}, \mathrm{ZrO}_{2}\right.$, as well as $\left.\mathrm{SiO}_{2}\right)$ were applied in dental composites. Several compressive, flexural strength, wear resistance and hardness tests have been implemented for the filler concentrations $(0.660 .2,0.3 .33,4.66,6$ and $8 \mathrm{wt} \%)$. Moderately light filled formulation ( $0.66 \mathrm{wt} \%$ of fillers) have been subjected to characterizing via significantly more elevated shrinkage in comparison to high filled ones. Yet, at high concentrations of fillers ( $8 \mathrm{wt} \%)$, a reduction in the mechanical characteristics has been seen. Strong Nanofiller-polymer interactions are of high importance for maximizing the micro-dispersions that is vital to achieve maximum levels of the mechanical characteristics. It can be seen that the flexural strength, wear resistance, and hardness will be increased with the increase in Nano-fillers content. Such observations are due to the fact that the Nano-fillers are considered to be reinforcing fillers that have efficient chemical features, surface activity, as well as non-uniform related to the porous surface that is contributing to highest interphase interactions between fillers and polymer chains. Generally, flexural strength, wear resistance, and hardness increase are considered to be caused by additional reinforcements that are related to polymer phase. The reinforcement degree is based on the extent of the filler interaction and the polymer.

Interactive forces will be increased with the Nano-filler concentrations as well as the reinforcement degree. As Nanofiller content increases, the polymer - filler interactions increase which cause the increase of hardness, flexural strength, and wear resistance because of the greater polymer matrixfiller particle interactions. The decrease in compression is due to the compression of the chains mobility resulting from the physical cross-links introduced via Nanofiller. Additional increase in the filler loadings will result in decrease in the molecular mobility because of the extensive formations related to the physical bonds that exist between polymer chains and the filler particles, which stiffen matrix, as the filler loadings get increased, the matrix will be increasingly becoming reinforced, therefore, reducing hardness, wear resistance, and flexural strength at any filler loading greater than $(4.66 \mathrm{wt} . \%)$.For Nanofiller, the lowest hardness, flexural strength, and wear resistance detected has been because of Nanofillers mean agglomerate particles sizes as well as the weak interactions between polymer matrix and the fillers. Such remarks have indicated that mean agglomerate particles sizes are of high importance in impacting the dental composite's mechanical properties. It has been 
also indicated that Nanofillers incorporations including ( $\mathrm{SiO} 2, \mathrm{ZrO} 2$, as well as $\mathrm{HA}$ ) in polymeric matrix have the ability of promoting enhancements in the chemical and also to the mechanical dental Nano-composite's properties. Fig. (2) shows the stepwise increasing trend of Nano dental composites' mechanical properties with increasing content of Nanofiller. The hardness, wear resistance, flexural strength, as well as the compressive related to Nano dental composite based on (4.66 wt.\%) loading increased respectively, which indicated the super-reinforcement of Nanofiller. When the, Nanofiller content was higher than (4.66 wt.\%), the slower improvement rate of the mechanical properties was due to the poor dispersion of Nanofiller, as the partial multi-layered Nanofiller would enhance the strength little. The interfacial area between Nano-filler layers and polymers are reduced due to the formation of Nano-filler aggregate, and that will result in low mechanical properties. There was an increase in the mechanical properties because of the high interfacial shear strengths between matrix and Nano-fillers because of creating supra molecular bonding and crosslinks that cover Nano-fillers and avoid cracks. Furthermore, optimum bonding between matrix and Nano-filler could change the crack propagation [15].

Optimum flexural strengths necessities efficient stress transferring from resins to Nano-fillers, while to suitable hardness, there will be a need for an increased filler volume fraction. The reason is obvious since composite strength depends on the load transfer between filler and matrix, and stiffness depends highly on particle loading. However, specific attention should be made on the particle shape of fillers since it has remarkable impact on certain dental composite's mechanical properties. According to the mechanical properties obtained in the presence of the same load of different Nanofillers, the reinforcing order can be written as follows-:

$$
\mathrm{HA}>\mathrm{SiO}_{2}>\mathrm{ZrO}_{2}
$$

The reinforcing effect of Nano HA (Nano hydroxyapatite is essentially due to the increase of filler particle's surface area due to the decreased particle sizes that will lead to elevated surface energy at filler-matrix interfaces. This will make the materials to have more strength and let them hold up in more efficiency when exposed to pressure (such as pressure resulted from chewing and biting). This will help in developing more effective material for fillings in the case when the fillings turn out to be inevitable.

a) Compression

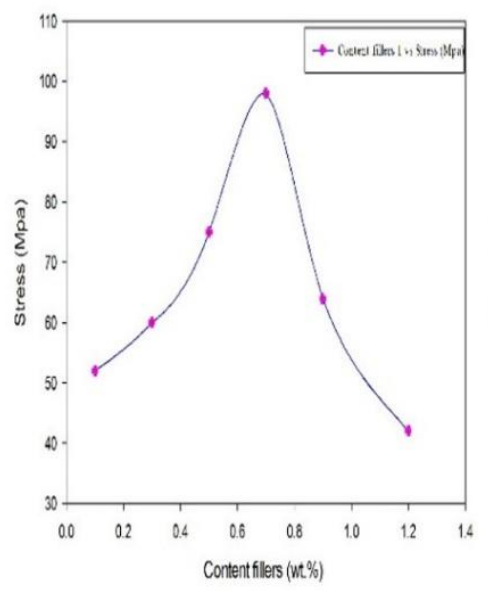

b) Flexural

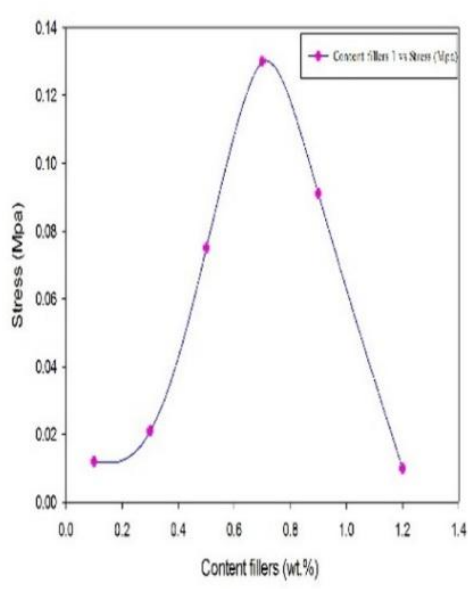

c) Hardness

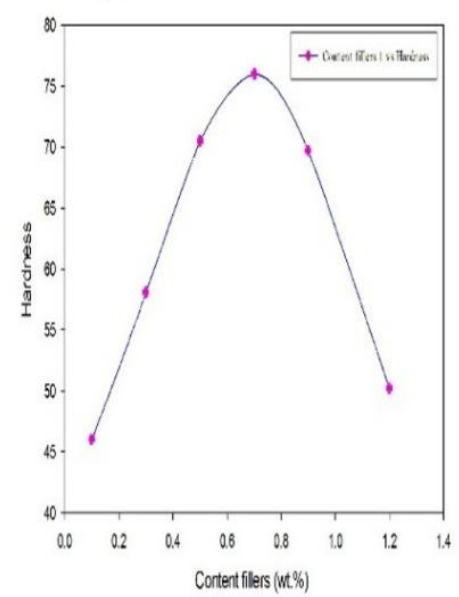

Fig. 2 ( $a, b$ and $c)$ : shows the effect of Nanofillers contact on the mechanical properties. 


\subsubsection{Flexural Strength and Elastic Modulus}

The main objective in this study was to study The flexural strengths of the composite samples containing various mass fractions of Nanofillers $\left(\mathrm{SiO}_{2}, \mathrm{ZrO}_{2}\right.$ and Hydroxyapatite) As shown in Fig 9, there is an initial increase in the flexural strength of the Nanoparticles filled composites as the filler content is increased from ( 0.66 to 8 ) wt.\%. However, a decrease in strength values is observed at higher values of filler addition. Going back to the results obtained for the flexural strength, it should be reminded that, one of the major factors affecting the mechanical characteristics of composite samples is extent of interfacial interaction. In other words, poor interfacial interactions prevent a sufficient transfer of stress between components. In such cases, the addition of filler particles is expected to increase the number of weak links and therefore have a negative impact on strength. Therefore, we believe that the increase in the strength shown in Fig 9 is due to the reduced macromolecular mobility in the matrix and the drop in the strength. Values is most likely attributable to the overcoming effect of poor filler/matrix coherence at higher values of the filler content

Spherical and evenly distributed micrometer size filler particles can be observed and a closer examination of this micrograph indicates that, as a result of a strong interfacial bond between the filler and resin, some filler particles have been effectively forced out of the matrix during the mechanical testing. The modulus of elasticity values were calculated from these data and are presented in Fig 9 . As indicated in this table, except for the case of the sample containing 4.6 wt.\% Nano fillers the increase in the content of the filler is accompanied with increased value of the elastic modulus. A possible explanation for the increased value of elasticity modulus is the more restricted motion of Bis-GMA matrix with an increase in the filler content [41]. Once again, at some critical value of the filler content the sample behavior is dominated by the poor bonding at the interface causing a decrease in modulus value. An exponential dependence of modulus of elasticity on filler content has already been reported in the literature [42]. Another point which can be concluded from the data is that there is no sign of plastic deformation prior to fracture in these samples .

These results show that all Nano particulate containing samples have significantly higher mean strength than those of the Nanofilled composite samples 1. This implies an effective stress transfer as a result of good bonding between the Nano-sized particles and the matrix. It is also important to take into account that the filler fraction values were lower in the Nano-size filler containing composites compared to the Nanofilled composite samples prepared in this study. In summary, the data presented in this study on the mechanical properties of the Nano-sized filler containing samples, indicates that in spite of the lower weight fraction, the use of Nano-size Nanofillers particles resulted in a considerable enhancement in the mechanical properties of the dental restorative composite samples. Obviously, several factors are at play, but we believe that maybe the most important is the favorable adhesion between the Nano-size filler and the polymeric matrix. Incorporating of Nanofillers in dental composites enhanced the flexural strength by over 100\%.The flexural strength enhancement may be a result of increased area of the surface of the particles of the filler due to the reduced size of the particle that produces high energy of the surface at interface of the filler-matrix . This results from the capability of those Nanoparticles in hindering the propagation of cracks within the matrix of the dental composite based on the mechanism of the strengthening, in addition to strong bonding between those particles and the resin matrix. Adding $\mathrm{HA}, \mathrm{SiO}_{2}$, and zirconium oxide as Nano-particles leads in increasing both dental Nano composites' flexural modulus and strength. The cause of this kind of behavior is that high shear strength of the interface, between matrix of the resin 
and the Nanoparticles of each of $\mathrm{HA}, \mathrm{SiO}_{2}$, and zirconium oxide associated with the creation of physical cross-link bonding shielding or covering Nano-particles, which successively prevent cracks from propagating inside the material, according to foregoing.

In addition to that, incorporating brittle Nano-particles in the matrix of the polymer enhances composite stiffness with the restriction of polymer chain mobility in Nanocomposite. And sufficient Nano-particle distribution, particularly at low Nano-particle additive percentages to composite materials, as it has been performed in the presented study (Nano-particle content's volumetric fraction in composites not higher than $18 \%$ ratio) which decreases Nano-particle agglomeration in the composite, which could result in the reduction from location and the density of stresses are insufficient for breaking weak interface interactions. Which is why, those small concentrations of the stress may be transferred easily from the matrix to brittle Nano-particles, thereby permitting particles in contributing their property of the high brittleness to composites therefore, it result in increasing both flexural modulus and strength.

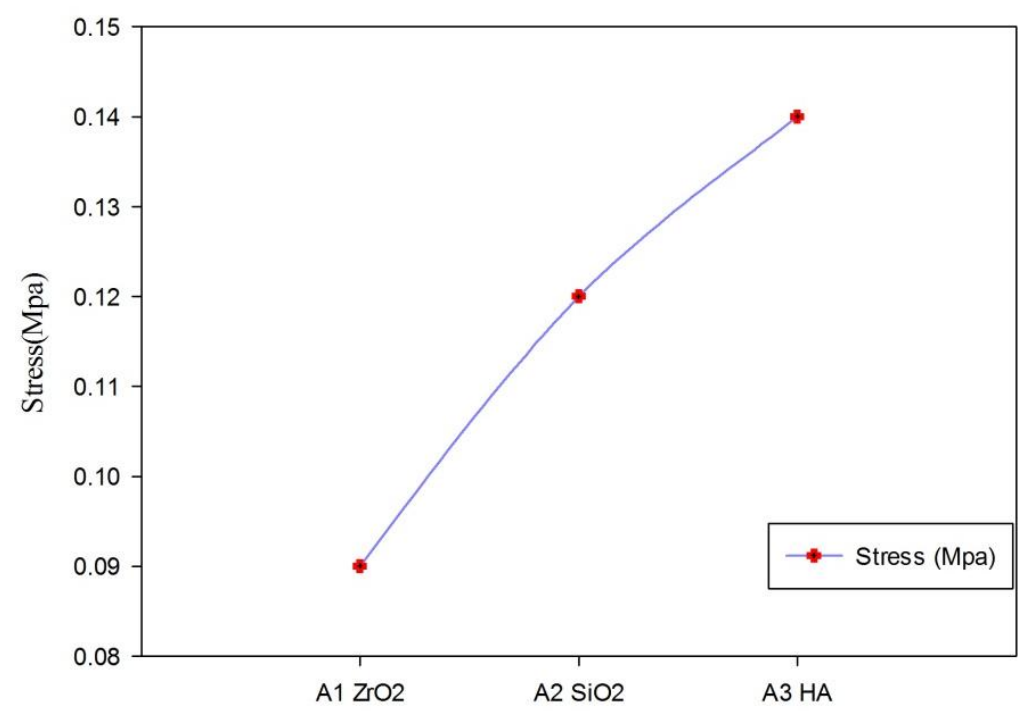

Fig 9: Show the flexural strength of Nanofiller- reinforced composite dental

\subsubsection{Compressive Strength}

The strength of Nanofillers reinforcement resin which is under compressive loading has been evaluated with the approach which is used to test Nanofillers. The values have been stated in Fig 10 for compressive strength values of synthetic polymer which has been reinforced by Nanofillers of a variety of average size of particles. Some other materials, which are presently in general utilization, have been illustrated for comparisons. Specimens which have been made by Nanofillers had were of high compressive strengths. Which gives the confirmation of the existence of differences that are statistically significant between all groups of samples. Moreover, the results of the compressive test have shown the differences amongst samples $\mathrm{SiO}_{2}(10-30 \mathrm{~nm})<\mathrm{ZrO} 2(20-30) \mathrm{nm}<\mathrm{HA}(60) \mathrm{nm}$. The testing of compressive strength is utilized to assess mechanical characteristics of this type of material. Due to the fact that the majority of the masticator loads belong to compressive forces class. There is a considerable importance in evaluating the resin material durability in that conditions [43]. Advancements that have been accomplished in the area of Nano-technology had a great influence on resins composition [44]. Many different types of composite were produced and presented according to the Nano-technology. There is an importance of compressive strength measuring in vitro research 
which were characterized as sufficient indicators for the simulation of functional forces which have loaded upon the restorative materials that are under mastication [45,46]. Consequently, in the present work, Nano-composite resin's compressive strength has been projected. Composite resins that are Nanofilled, combined with Nano cluster formulations (that reduce filler particles' interstitial spacing) to Nanosized particles. Which presents higher loading of the filler, advanced physical characteristics, in comparison to these complexes. The average sizes of filler particles range between $(10 \mathrm{~nm}$ and $30 \mathrm{~nm})$. Spherical shapes include numerous benefits such as improvements in the filler load of the composites as well as increasing fracture strengths due to the fact that mechanical stresses tend to be concentrated on filler particles' angles and protrusions. The majority of the Nanocomposites have filler particles that are spherically-shaped that have improved filler load . In the present research, Nano-composites have higher compressive strengths compared to compressive strengths of the other dental-composite. The present research agrees in increased strength value of the Nano-composite resin. It has appeared that besides greater sizes of filler particles in dental composite resins, the existence of $\mathrm{SiO}_{2}$, hydro-apatite, and zirconium fillers have a significant role in its enhanced strength. The existence of aromatic cycles in the monomers such as Bisphenol dimethacrylate and Bis-GMA has been detected in dental composites results in reducing cyclizing and increasing cross linking in the polymer and provides consecutive enhancement in strength/durability and mechanical characteristics. None-the-less, in acrylate and TEGDMA monomers particularly as a result of its high flexibility, there's more chance of intermolecular cyclizing. In a way that Bis-GMA stiffness is a factor in improving compressive strength as well [47]. Esthetic properties of the Nanocomposites are analogous to the esthetic characteristics of the natural teeth. Due to the fact that they are of a sufficient wear resistance they result in no enamel wear of analogous teeth. Their polymerization shrinkage is quite minor, which is why, they have less tension which results in decreasing of the over-sensitivity of post-op. there are filler particles in the Nano-composites, they enhance the strength of the matrix and produce higher toughness to fractures [48, 49]. Therefore, Nano-composites are of compressive strengths which are higher, which have been utilized in the present research where their higher strength may be clarified with their higher loadings of the filler. There have been numerous researches that reported the correlation between the volume fraction and the mechanical characteristics of the fillers [50-52].

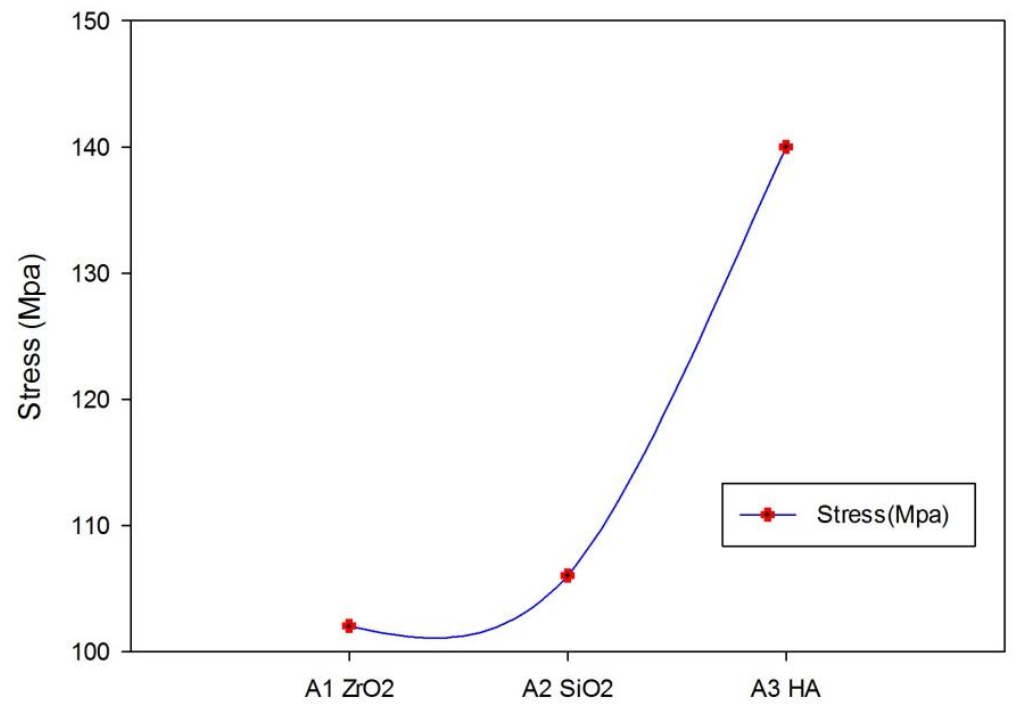

Fig 10: Compressive strength of Nanofiller- reinforced composite dental 


\subsubsection{Wear resistance}

Composite wear is a complicated process which is dependent on numerous external and internal variables like the structure of the surface, lubricant, contact stress, wear duration, temperature [53], and properties of the material, which includes the level of the filler, polymerization degree, conditioning [54], performance of the operator, surface area and type of cavity, and/or restoration area [55,56]. Experimental Nano-filled dental compounds wear is going to be evaluated. Complexes are going to be prepared at a variety of Nano-fillers, measured mechanically and tested under the wear mode. The samples of the complexes are going to be analyzed afterwards for the determination of the wear mechanisms. The aim of those tests are both for understanding Nano-filled complexes wear behavior. The test results of wear resistance for each one of the 3 samples. Fig 11 states the average of the values of the wear loss (concerning weight loss) .

The fig (11) that show a smaller value of weight loss provide more resistance to wear. It is believed that it is a result of the more efficient treated Nanofillers bonding to the composite. Wear resistance for (A3) composite have proven considerably higher compared to composite (A1 \&A2) wear resistance. The results of the wear may be justified by filler particles' size. Some of the experts hypothesize that complexes which contain smaller particles of filler have shown a more substantial resistance to wear. i.e., less wear rate when Nanocomposite for ( $\mathrm{ZrO} 2, \mathrm{SiO} 2$, and $\mathrm{HA})$ has been increased [57]. Which can be explained by the fact that increasing added particles' percentage enhances the hardness as exhibited from the results of hardness test, due to the fact that hardness is inversely proportionate to the rate of wear due to the fact that it decreases plastic deformation [58].

Besides the impact of those particles in load carrying (pressure extruded) and being directly in contact with disk due to the fact that it decreases contact area between the hard disk and the sample (model). Results have shown that Nano-filled complex resin with lower size of particles in the range between $(10 \mathrm{~nm}$ and $30 \mathrm{~nm})$ is of a lower wear. The reduction of the particle size of the filler with the increase in the loading of the filler, wear resistance was enhanced [57,58]. Filler particle type could as well have an impact on the process of the wear, $\mathrm{HA}, \mathrm{ZrO}_{2}$ and $\mathrm{SiO}_{2}$ which contains resin composite has shown more efficient resistance to wear. For the best mechanical and physical restoration characteristics, the content of residual monomer has to be reduced as much as possible and the conversion percentage to polymer has to be increased as much as possible [59]. The claim was that in resins of Nano-filled composite most TEGDMA (tri [ethylene glycol] di-methacrylate) was used in combination with acrylate monomers and Bis-EMA (Bisphenol A poly-ethylene glycol diether dimethacrylate). All those resins are of a higher molecular weight and have a smaller number of double bonds for each unit, and that enhances the cure degree of polymer matrix, and as a result, the resistance to wear [60]. Using finer filler particles causes a decrease in the interparticle spacing as well as a decrease in the wear [61]. 


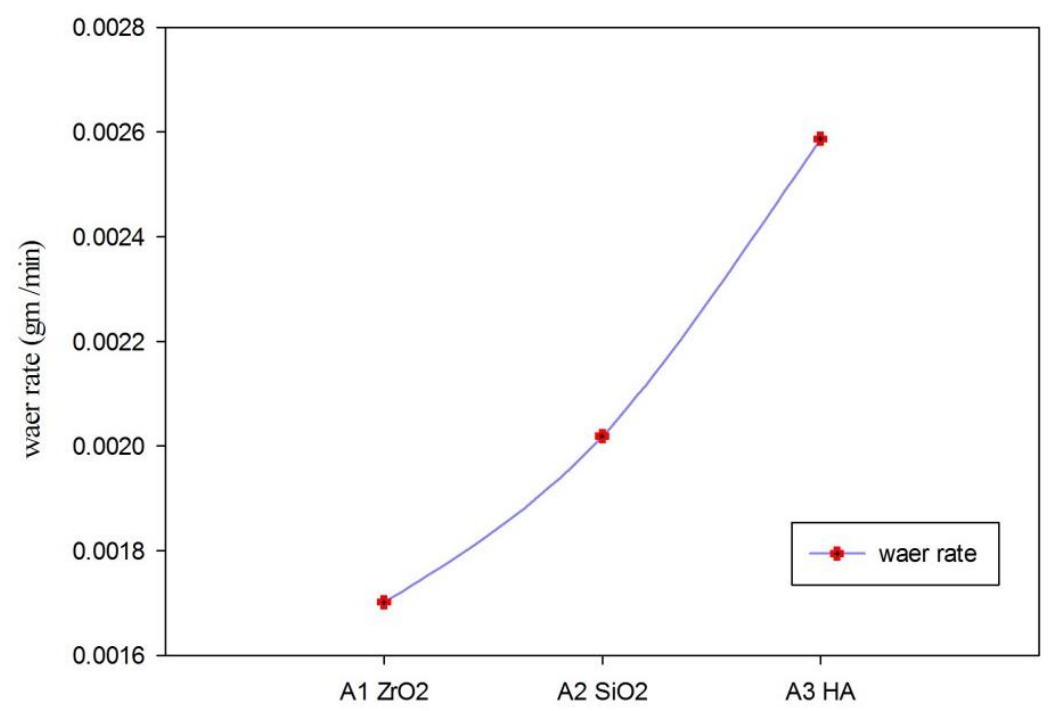

Fig 11: wear strength of Nanofiller- reinforced composite dental

\subsubsection{Hardness}

Hardness measures the resistance of solid matter to different types of long-lasting changes in the shape in the case of applying compressive forces. Some of the materials (such as the metal materials) are harder compared to others (such as plastic materials). In general, macroscopic hardness is identified with strong inter-molecular bonds, however, solid materials' behavior under forces is complicated; which is why, there is a variety of hardness measures, such as: indentation hardness, rebound hardness scratch hardness. Hardness depends on elastic stiffness, strain, plasticity, toughness, ductility, viscosity, viscoelasticity, and strength. Some of the typical hard matter examples are concrete, ceramics, some metals, and super hard materials that may be contrasted by soft matte.

The hardness of the composites was also due to the destruction of the mobility of the dental composite matrix by the addition of the filler content. This may be attribute to increasing the surface area of the Nano fillers in contact with dental composite and decreasing the movement of polymer molecular which lead to reduce the strength of material. The existence of particles of filler in resin matrix improves some mechanical characteristics, like hardness [62,63], adding Nanoparticles to dental composite resin with (1.33 to 6.6) wt\% loadings considerably enhances hardness at $1.33 \mathrm{wt} \%$, followed by (6.6wt)\%. [64]. Vojdani et al. [65], have utilized $\mathrm{ZrO}_{2}, \mathrm{SiO}_{2}$ and hydroxyapatite with a $3 \mu \mathrm{m}$ average size of particles to the dental composite; they have noticed a significant increase in the hardness .

The size of the filler has an impact on composite hardness [66]. Dental complexes that have been reinforced with Nano-particles have shown high values of hardness [67-69] Liu et al. have stated a considerable increasing in dental composite hardness, which have been reinforced with the Nanofillers. All the groups have shown mild increase in the values of hardness. Dental composite hardness, that have been reinforced by Nano-fillers which consist of $\mathrm{ZrO}_{2}, \mathrm{SiO}_{2}$, and $\mathrm{HA}$, have given results that have shown that (HA )have had an impact on the significant increase in hardness [70]. As it is exhibited in fig. 12, there has been an increase in the hardness with the increase in the volume fraction of the filler . 


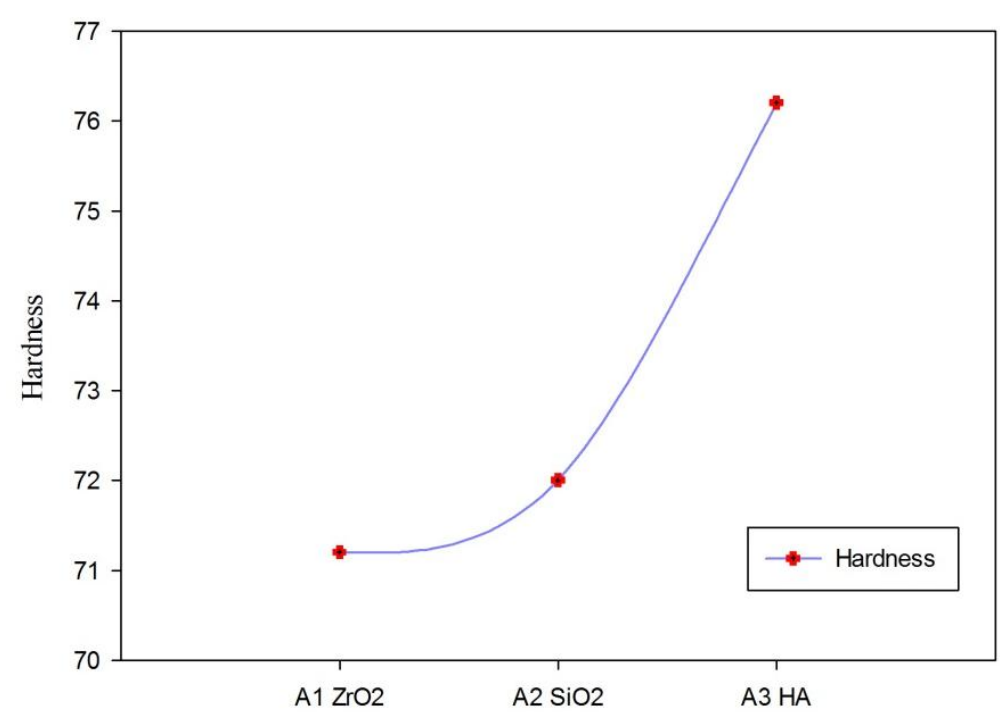

Fig 12: Hardness strength of Nanofiller- reinforced composite dental

\section{Conclusions}

This work has been focused on synthesizing a new Bis-GMA-based composite resin with Nanofillers (HA, $\mathrm{SiO}_{2}$, and $\mathrm{ZrO}_{2}$ ) for the use in the field of dentistry as restorative material. The filler that has been newly synthesized was a powder of white color, with carefully chosen particle sizes. The use of Nano-sized fillers particles has proven highly effective in the improvement of mechanical characteristics. Another benefit of the Nano-size reinforcement agents in comparison with the micro-sized particles has been the lower loading requirement. The enhanced mechanical characteristics which are shown by the complexes that include Nanoparticles is mostly a result of more efficient interaction of filler/polymer. A Nano-particle dispersion of higher efficiency, in combination with higher loadings could result in a more enhanced complex dental restorative materials. Additional researches are required for improving interactions between Nano-sized fillers and matrix phase and in addition to that, increasing Nano-filler particles' loading capacity to the matrix of the polymer. In spite of the limitations of the present study, it might be concluded that dental Nanocomposites that are synthesized have several advantages, such as better water resistance and lower volumetric shrinkage. Even though the dental composite water solubility was small.

\section{References:}

[1] Bayne SC, Heymann HO, Swift EJ Jr. Update on dental composite restorations. J Am Dent Assoc 1994;125(6):687-701.

[2] Kramer N, Garcia-Godoy F, Frankenberger R. Evaluation of resin composite materials. Part II. In vivo investigations. Am J Dent 2005;18:75-81.

[3] Yap AU, Lim LY, Yang TY, Ali A, Chung SM. Influence of dietary solvents on strength of nanofill and Ormocer composites. Oper Dent 2005;30(1):129-133.

[4] Dewaele, M.; Truffier-Boutry, D.; Devaux, J.; Leloup, G. Volume contraction in photocured dental resins: The shrinkage-conversion relationship revisited. Dent. Mater. 2006, 22, 359-365.

[5] Ferracane, J.L. Developing a more complete understanding of stresses produced in dental composites during polymerization. Dent. Mater. 2005, 21, 36-42. 
[6] Calheiros, F.C.; Sadek, F.T.; Braga, R.R.; Cardoso, P.E. Polymerization contraction stress of lowshrinkage composites and its correlation with microleakage in class V restorations. J. Dent. 2004, 32, 407-412.

[7] Tantbirojn, D.; Versluis, A.; Pintado, M.R.; DeLong, R.; Douglas, W.H. Tooth deformation patterns in molars after composite restoration. Dent. Mater. 2004, 20, 535-542.

[8] RG C. Chemistry, composition, and properties of composite resins. Dent Clin North Am 1981; 25: 219239.

[9] Tian, M., Gao, Y., Liu, Y., Liao, Y., Hedin, N. E. \& Fong, H. (2008). Fabrication and evaluation of BisGMA/TEGDMA dental resins/composites containing nano fibrillar silicate. Dent. Mater., 24(2), 235243.

[10] Ikeda I, Otsuki M, Sadr A. Effect of filler content of flowable composites on resin-cavity interface. Dent Mater J 2009; 28: 679-685.

[11] Sakaguchi RLPJ. Craig's restorative dental materials. Elsevier 2012.

[12] Barszczewska-Rybarek, I.M. Characterization of urethane-dimethacrylate derivatives as alternative monomers for the restorative composite matrix. Dent. Mater. 2014, 30, 1336-1344.

[13] Barszczewska-Rybarek, I. Structure-property relationships in dimethacrylate networks based on BisGMA, UDMA and TEGDMA. Dent. Mater. 2009, 25, 1082-1089.

[14] Sideridou, I.; Tserki, V.; Papanastasiou, G. Effect of chemical structure on degree of conversion in light-cured dimethacrylate-based dental resins. Biomaterials 2002, 23, 1819-1829.

[15] ISO 178: 2003. Plastics-Determination of flexural properties; International Organization for Standardization: Geneva, Switzerland, 2003.

[16] Katsikis N, Franz Z, Anne H, Helmut M, Andry V. Thermal stability of PMMA /silica Nano-and micro composite as investigated by dynamic-mechanical experiment. Polym Degra and stability 2007; 22: 1966-76.

[17] ISO 2039-1: 2004. Plastics-Determination of hardness-Part 1: Ball indentation method; International Organization for Standardization: Geneva, Switzerland, 2004.

[18] 198. Silverstien,R.M.; Webster, F.X and Kiemle, D.J. Spectrometric identification of Organic compound 7th ed .Joun Wiley and Sons. 2005.

[19] Pretsch, E.; Buhlmann, P.; Baderscher, M. Structure determine of Organic compound 4th ed .springerVerlag Berlin Heidelberg 2009.

[20] Vinícius E. S. Gajewski et al, Monomers Used in Resin Composites: Degree of Conversion, Mechanical Properties and Water Sorption/Solubility, Braz Dent J (2012) 23(5): 508-514.

[21] Lemon MT, Jones MS, Stansbury JW. Hydrogen bonding interactions in methacrylate monomers and polymers. J Biomed Mater Res A 2007;83A:734-746.

[22] Sideridou I, Tserki V, Papanastasiou G. Study of water sorption, solubility and modulus of elasticity of light-cured dimethacrylatebased dental resins. Biomaterials 2003;24:655-665.

[23] Pfeifer CS, Shelton ZR, Braga RR, Windmoller D, Machado JC, Stansbury JW. Characterization of dimethacrylate polymeric networks: A study of the crosslinked structure formed by monomers used in dental composites. Eur Pol J 2011;47:162-170.

[24] Stansbury, J.W.; Antonucci, J.M. Dimethacrylate monomers with varied fluorine contents and distributions. Dent. Mater. 1999, 15, 166-173.

[25] Chang, M.C.; Lin, L.D.; Chuang, F.H.; Chan, C.P.; Wang, T.M.; Lee, J.J.; Jeng, P.Y.; Tseng, W.Y.; Lin, H.J.; Jeng, J.H. Carboxylesterase expression in human dental pulp cells: Role in regulation of Bis-GMAinduced prostanoid production and cytotoxicity. Acta Biomater. 2012, 8, 1380-1387. 
[26] Yamazaki, N.; Kurata, S. Synthesis of dimethacryloxy ethyl-1,1,6,6-tetrahydro-perfluorohexamethylene-1,6- dicarbamate as dental base monomers and the mechanical properties of the copolymers of the monomer and methyl methacrylate. Dent. Mater. J. 2011, 30, 103-108.

[27] M Giannini et al, Characterization of Water Sorption, Solubility, and Roughness of Silorane- and Methacrylate-based Composite Resins, Operative Dentistry, 2014, 39-3, 264-272.

[28] Van Krevelen, D.W., Properties of polymer, 3rd ed.; Elsevier, Amsterdam, 1990.

[29] Dickens, S.H. and Cho, B.H., "Interpretation of bond failure through conversion and residual solvent measurements and Weibull analyses of flexural and microtensile bond strengths of bonding agents", Dent. Mater., 21(2005) : 354-364.

[30] Santos, R.L. Clarke, M. Braden, F. Guitian and Davy, K.W.M., "Water absorption characteristics of dental composites incorporating hydroxyapatite filler", Biomaterials, 23(2002): 1897-1904.

[31] Labella R, Lambrechts P, Van Meerbeek B, Vanherle g. Polymerization shrinkage and elasticity of flowable composites and filled adhesives. Dent Mater 1999;15:128-37.

[32] Stansbury JW. Cyclopolymerizable monomers for use in dental resin composites. J Dent Res 1990;69:844-8.

[33] Feilzer AJ, Dauvillier BS. Effect of TEGDMA/BisGMA ratio on stress development and viscoelastic properties of experimental two-paste composites. J Dent Res 2003;82:824-8.

[34] Ferracane JL, Greener EH. The effect of resin formulation on the degree of conversion and mechanical properties of dental restorative resins. J Biomed Mater Res 1986;20: 121-31.

[35] Braga RR, Hilton TJ, Ferracane JL. Contraction stress of flowable composite materials and their efficacy as stressrelieving layers. J Am Dent Assoc 2003;134:721-8.

[36] Calheiros FC, Sadek FT, Braga RR, Cardoso PEC. Polymerization contraction stress of low-shrinkage composites and its correlation with microleakage in class V restorations. J Dent 2004;32:407-12.

[37] Tarasov, A." thermal analysis: methods, principles, applicason." lecture on thermal analysis. 2012, 26:16.2012.

[38] Cantre,K. B.; Martin J. H.; Ro, K. S. " Application of Thermogravimetric Analysis for the Proximate Analysis of Livestock Wastes". Journal of ASTM International. 2009, 7(3)P:2-13.

[39] Adivarekar, R.v.; dasarwar, S.D.; Khurana, N.S. "synthesis of halogen free flame retardant and application polypropylene." indian journal of fibre \&textile research vol 2012, 38:pp:9-13.

[40] Wunderlich, B. Thermal Analysis, text for an audio course. ATHAS, Advanced Thermal Analysis. Alaboratory for Research and Instruction. 1981.

[41] Asmussen, E., and Peutzfeldt, A., "Mechanical properties of heat treated restorative resins for use in the inlay/onlay technique", Scan. J. Dent. Res., pp. 564-571, 1998.

[42] Willems, G., Lambrechts, P., Braem, M., Celis, J. P., and Vanherle, G., "A classification of dental composites according to their morphological and mechanical characteristics", Dent. Mater., Vol. 8, pp. 310-318, 1992.

[43] Mohandesi JA, Rafiee MA, Barzegaran V., "Compressive fatigue behavior of dental restorative composites", Dent. Mater J. 2007; 26: 827-837.

[44] Ure D, Harris J., "Nanotechnology in dentistry: Reduction to practice", Dentistry Update 2003; 30: 1015.

[45] Anusavice KJ. 2003, "Phillips Science of Dental Materials", Edition t, editor: Saunders, p 832.

[46] Powers JM., Sakaguchi RL., 2006, "Craig's restorative dental materials: Mosby Inc. Ratanapridakul K, Leinfelder K, Thomas J. 1989, "Effect of finishing on the in vivo wear rate of a posterior composite resin", The Journal of the American Dental Association 118(3):333-335. 
[47] Elliot JE, Lovell LG, Bowman CN, "Primary cyclization in the polymerization of bis-GMA and TEGDMA: a modeling approach to understanding the cure of dental resins", Dent. Mater. 2002; 17: 221-229.

[48] Yap A., "Comparison of surface finish of new aesthetic restorative materials", Oper. Dent. 2004; 29:100-104.

[49] Chen MH., Sun SP., Su WF., "Low shrinkage light curable nanocomposite for dental restorative material", Dent. Mater., 2006; 222: 138-145.

[50] Braem M, Finger W, Van Doren VE, Lambrechts P, Vanherle G. 1989, "Mechanical properties and filler fraction of dental composites", Dental Materials 5(5):346-349.

[51] Chung K, Greener E. 1990, "Correlation between degree of conversion, filler concentration and mechanical properties of posterior composite resins", Journal of Oral Rehabilitation 17(7): 487-94.

[52] Khaled A N., "Physical Properties of Dental Resin Nanocomposites", Master thesis, University of Manchester School of Dentistry, 2012.

[53] Sarkar AD. Dental tribology. Friction and Wear. London: Academic Press; 1980.

[54] Condon JR, Ferracane JL. In vitro wear of composite with varied cure, filler level, and filler treatment. J Dent Res. 1997;76(7):1405-11.

[55] Palaniappan S, Bharadwaj D, Mattar DL, Peumans M, Van Meerbeek B, Lambrechts P. Nanofilled and microhybrid composite restorations: Five-year clinical wear performances. Dent Mater. 2011;27(7):692-700.

[56] Palaniappan S, Elsen L, Lijnen I, Peumans M, Van Meerbeek B, Lambrechts P. Nanohybrid and microfilled hybrid versus conventional hybrid composite restorations: 5-year clinical wear performance. Clin Oral Investig. 2012;16(1):181-90.

[57] Hassan AM, Mayyas AT, Mohammed AA, Hayajneh T. Wear Behavior of AL - Cu and AL - Cu / Sic Components Produced by Powder Metallurgy, Springer Science + Business Media, Published online 24 June. 2008:5368-5375.

[58] Gul F, Acilar M. Effect of the Rein for Cement Volume Fraction on the Dry Sliding Wear Behavior of AL - $10 \mathrm{Si} / \mathrm{Si} \mathrm{Cp}$ Composites Produced by Vacuum Infiltration Technique. Composites Science and Technology 2004;64:1959-1970.

[59] G. Willems, P. Lambrechts, M. Braem and G. Vanherle, "Composite Resins in the 21st Century," Quintessence In- ternational, Vol. 24, No. 6, 1993, pp. 641-658.

[60] 3M Dental Products FiltekTM Supreme Universal Restora-tive System, Technical Product Profile St. Paul MN 55144-1000, 2002.

[61] K. D. Jǿgensen and E. Asmussen, "Occlusal Abrasion of a Composite Restorative Resin with Ultra-Fine Filler," Quintessence International, Vol. 9, No. 6, 1978, pp. 73- 78.

[62] Culhaoglu, A. K. \& Park, J. (2013). A comparison of the wear resistance and hardness of two different indirect composite resins with a ceramic material, opposed to human enamel. Eur. J. Gen. Dent., 2(3), 274-280.

[63] Shokrieh, M. (2014). Residual stresses in composite materials. London: Woodhead Publishing.

[64] Leitune, V. C. B. et al. (2013). Niobium pentoxide as a novel filler for dental adhesive resin. J. Dent., 41(2), 106-113.

[65] Vojdani, M., Bagheri, R. \& Khaledi, A. A. R. (2012). Effects of aluminum oxide addition on the flexural strength, surface hardness, and roughness of heat-polymerized acrylic resin. J. Dent. Sci., 7(3), 238244.

[66] Monfared, M., Mirdamadi, S. \& Khavandi, A. (2013). Synthesis of new dental nanocomposite with glass nanoparticles. Nanomed. J., 1(2), 107. 
[67] Hubbezoglu, I. et al. (2007). Microhardness evaluation of resin composites polymerized by three different light sources. Dent. Mater. J., 26(6), 845- 853.

[68] Jain, S. et al. (2013). Nanotechnology: An emerging area in the field of dentistry. J. Dent. Sci., 1-9.

[69] Junior, R. et al. (2007). Flexural strength and modulus of elasticity of different types of resin-based composites. Braz. Oral Res., 21(1), 16-21.

[70] Safarabadi, M., Khansari, N. \& Rezaei, A. (2014). An experimental investigation of HA/AL2O3 nanoparticles on mechanical properties of restoration materials. Eng. Sol. Mech., 2(3), 173-182. 